\title{
MATTER, MAN, UNIVERSE: THE ONTOLOGY OF HUMAN OPENNESS TO THE COSMIC HOLISM
}

\author{
JAVIER MONSERRAT \\ Universidad Autónoma de Madrid
}

\begin{abstract}
The universe we know is a product of the human mind. In the primordial phenomenological experience, which man has of himself, two phenomenological facts are imposed: the experience of a stable world of objects and the experience of a world of fields of reality. The exercise of reason, which is given to man evolutionarily, leads to ask what are the real causes that produce these two worlds. Likewise, what is the ultimate truth of the universe. Modern science produces a rational (scientific) knowledge that provides the basis to answer those questions. Classical mechanics explains what is and how a macroscopic world of stable objects is produced. Quantum mechanics, what they are and how the fields of reality are produced, to which man accesses from his human psyche. All this leads us to understand that the universe has a holistic ontology (a way of being). Man, already by his primordial self-experience, but also by the results of science, remains open to the knowledge of cosmic holism. The holistic nature of the universe is the key to addressing the questions surrounding its ultimate truth. Holism continues to make possible the atheistic hypothesis of a universe without God. But it is also true that, beyond nineteenth-century reductionism, holism makes the hypothesis of the existence of God much more plausible today. As a suggestion, the article concludes with a reference to the image of God, and the creation of the universe in God, according to the allegorical discourse of Jewish kabbalah.
\end{abstract}

KEY WORDS: phenomenology, stable objects, fields of reality, classical mechanics, quantum mechanics, holism, psychic holism, cosmic holism, metaphysical hypotheses about the universe, mystic, Tzim-Tzum, Jewish kabala.

\section{Materia, hombre, universo: la ontología de la apertura humana al holismo cósmico}

RESUMEN. El universo que conocemos es un producto de la mente humana. En la experiencia fenomenológica primordial, que el hombre tiene de si mismo, se imponen dos hechos fenomenológicos: la experiencia de un mundo estable de objetos y la experiencia de un mundo de campos de realidad. El ejercicio de la razón, que le viene dada al hombre evolutivamente, lleva a preguntar cuáles son las causas reales que producen esos dos mundos. Igualmente, cuál es la verdad última del universo. La ciencia moderna produce un conocimiento racional (científico) que ofrece la base para responder esas preguntas. La mecánica clásica explica qué es y cómo se produce un mundo macroscópico de objetos estables. La mecánica cuántica qué son y cómo se producen los campos de realidad, a los que accede el hombre desde su psique humana. Todo ello nos lleva a entender que el universo tiene una ontología (un modo de ser real) holístico. El hombre, ya por su auto-experiencia primordial, pero también por los resultados de la ciencia, queda abierto al conocimiento del holismo cósmico. La naturaleza holística del universo es la clave para abordar las preguntas en torno a su verdad última. El holismo sigue haciendo posible la hipótesis atea de un universo sin Dios. Pero también es verdad que, más allá del reduccionismo decimonónico, el holismo hace hoy mucho más verosímil la hipótesis de la existencia de Dios. A modo de sugerencia, el artículo concluye con una referencia a la imagen de Dios, y de la creación del universo en Dios, según el discurso alegórico de la kabala judía.

PALABRAS CLAVE: fenomenología, objetos estables, campos de realidad, mecánica clásica, mecánica cuántica, holismo, holismo psíquico, holismo cósmico, hipótesis metafísicas sobre el universo, mística, Tzim-Tzum, kabala judía. 
1. Introduction. Start Point, PHENOMENOLOGy OF THE HUMAN FACT

We know that phenomenology (not in a strict philosophical sense, but according to the use that is made of this concept in the current human sciences), in its anthropological or psychological sense, is the science that describes the way in which human self-experience is presented to man himself. It describes, then, the facts apprehended, felt or perceived by man. That is, it describes the way in which man perceives himself as inserted in the universe.

Phenomenology is the knowledge of how the "fact» of the ordinary human experience of the universe is presented, that is, the experience of matter, of the universe, of the human body and of psychic life itself. However, the description of the "fact» involves making a qualitative selection of concepts and, from it, the construction of a description, also qualitative, of the type of experience of the reality that they denote. This knowledge, then, is a product of human mind. Thus, for example, Edelman or Gibson offer a basic phenomenological description that, although it coincides in common features, is substantially different. They do not say the same in all their details.

Phenomenology, for some, wants to be a science. Another thing is that you can get it, because its contents give rise to different versions and nuances. Not all phenomenologists agree to outline what constitutes the basic phenomenological experience. Therefore, phenomenology could be considered a science in formation: in search of the facts that should constitute its content. In fact, the stable scientific consensus on the proper way to describe how man warns himself in the universe has not yet been formed. Therefore, it could be admitted that instead of «science» we could spoke of phenomenology as a discipline of knowledge, on the way to the rigor proper to science.

\subsection{The phenomenology of human fact: the reality that prevails}

The «humanfact» as a scientificexplicandum. Although it is difficult to describe the human fact (remember that Teilhard spoke of the "human phenomenon»), science can not be constructed without describing "phenomenologically» facts that must be explained. These facts are the explicandum of science: what must be explained by science. Now, what is to explain? It is simply to refer the facts to the real causes that produce the existence and actual constitution of these facts (these causes are the explicans, which explains why the facts are real). Thus, for example, the fact or actual phenomenon of the existence of objects made of «something» (which we must describe as phenomena) is addressed in the explanations of physical science. The fact of the appearance of certain biological formations that we call "cancer» (which we must describe as a phenomenon) produces investigations oriented to know their causes. The fact that we are aware of our human body, our psychic constitution, our mind and our reason, as facts imposed by our immediate experience (which we must also describe as phenomena), leads us to ask ourselves, in the human sciences, what 
are the real causes that explain that we have a body, a sensitivity-conscience, a rational mind; In short, that we are men, as we warned.

If by ontology we understand the discipline of knowledge that seeks to know the real being of things, the things that are real and exist before us, that is, to know their causes, then we could say that the ontology seeks to know, in harmony with the knowledge produced by science, the nature and the causes of the real being of the universe.

a) The human self-experience in a universe of objects. Every man takes phenomenological awareness of himself as an object that is, in fact, situated in a universe of objects. Feeling and perceiving objects, and the actual being as object, means that each object is perceived as an entity (a real being) closed in itself, with an autonomy, an independence from other things and objects. The object, in front of the outside world and in front of the other objects, maintains a frontier that preserves it from being diluted in others, or in a universal environment without differences. Between some objects and others there are distances in a space and in a time that seems to contain them. On the other hand, in this universe of objects man is in fact seen as an object with unique properties. Properties that are also common to other objects, to certain classes of objects. It is, namely, a biological object and, in addition, a human object.

b) The self-experience of immersion in reality fields. Man, in fact, is not only perceived as an object. We say that also, phenomenologically, is immersed in fields of reality. This opening is based on the fact that the human object, physical and biological, possesses, in fact, as something that is imposed, a psychic condition. Consciousness is the essential property of the psyche. By conscience the man warns his own body. But it is the experience of the body as a field of reality. The whole body, in the unity of sensation-perception-consciousness, is seen as a field of reality, unitary, encompassing a multitude of objects integrated into the totality of the human object (this is what we call proprioception as a field of reality). But, in addition, by the external sensory-perceptual systems (vision, hearing, proprioception by immersion in the gravitational and magnetic fields of the universe ...), man has the openness to the experience of the world as a field of reality: he observes by vision the other objects and perceives the field of space in the passage of time; he feels and perceives himself as an object; he feels the immense experience of the auditory field that fills the external world visually perceived; feels the gravitational-magnetic experience of being immersed in an external field of reality that contains it, together with all other objects. In addition, the psychic, sensitive-perceptive-conscious condition that installs man in the world is what also allows human self-experience as a psychic subject: as an object that, thanks to its psychic constitution, drives the actions that are they orientate to the optimal survival in the environment (in the field of external reality that contains the human object and that allows it to move and be the protagonist of its survival actions). This survival is directed by the human psyche, by the psychic subject, which, in fact, also presents itself with 
functions that we designate as mind, rational human mind (distinct from the mind proper to animals, also present in the field of reality).

\subsection{The human fact and its possibilities emerged from the universe}

The field of reality as a field of possibilities: object and field. The fact that the universe, that man sees, is constituted by objects and that, at the same time, it is a universe of fields that founds the sensation-perception-consciousness, that allows the opening to the experience of that world of objects, it is the cause that makes human existence possible. Indeed. That the world is formed by objects that maintain their permanence, independence and autonomy, makes it possible for man to possess a stable body, and a rational mind that allows him to direct his actions, make his personal life by his own decisions and build his biography, his own story. Being an object, man can be master of himself. Man is possible because he exists in a universe of permanent objects, at least in sections of the temporal course of the universe. At the same time, on the other hand, the sensation-perception-consciousness of a field of reality, based on the psychic condition, is what allows the perception of a world of objects, and of the body itself. Man can know the world, and move in it to build his own life, because that world is not only a world of objects, but also a world of fields. This balance between objects and fields is what, in fact, as man warns in fact, is what makes human life possible.

If only «objects» existed and were real, locked in themselves, and in relation to other objects by blind, mechanical, gravitational or electromagnetic forces, human life would not be possible. The opening to fields of reality by consciousness makes possible knowledge and the knowledge of the world in which life should be built. The experience of life, of oneself, of non-living and living objects, of space and time, of the forms of things, of light, of colors... all this fuses the deepest emotions that lead to poetry and to undertake the adventure of life. Through the senses we have access to know the beauty of that world constituted by «objects».

Holism. The term holism (holos, in Greek) refers to the whole, to the totality. Therefore, having a holistic experience means having the experience of something as a whole. Cosmic holism means the experience of the universe as a whole, as a unit of which everything is a part. Well, thanks to the experience of the fields of reality, man has a holistic experience of the universe. The cosmos is not an aggregate of objects independent of one another, distanced in spacetime and connected by blind mechanical forces, but the universe produces immense fields of consciousness in which everything is integrated into a unit that encompasses everything. Thus, man feels attached to all the objects of the universe by vision, he feels immersed in the fields of light that show the beauty of reality. Holism, as an experience of the universe, is not a philosophical concept or a scientific construct. It is, first of all, a phenomenological experience. It is a fact that is imposed on human self-experience. 


\subsection{The rational man, measure of all things}

The fact of the existence of man - I say «done» because it is something primordial that is presented- is the beginning of everything. Everything begins because man has experience of himself, of his psyche, of his capacity of sensation-perception-consciousness, of his condition of psychic subject that directs his actions in the world, oriented to survival... Man finds himself in the world as a fact. It is true that man's experiential existence has arisen from a long past, in space and time. A long evolutionary process. But man has no knowledge of what that past may have been like. However, the fact is that man is there, he knows himself and has constituted a psyche, with sensationperception-consciousness, and, this is very important, with a rational capacity. Man, starting from the given conditions in fact, makes use of his reason to guide his actions.

Man is the measure of all things. That is, everything we know, of ourselves and of the universe, physical and biological, is through man: man feels, knows, shapes, conceptualizes, delimits, all things. It is not possible to know neither matter, nor the universe, nor man, as they are in themselves, apart from man. In the human consciousness appears the experience of the psyche itself, of the body itself, of the objects of the world, of the forms of things, of space-time, of light and of the universe. Human reason is also known and the way it works, as it is imposed after an unknown origin. The universe of our experience is not the universe itself, but the universe approached from man, from his consciousness and sensory-perceptual-conscious system.

The exercise of reason, in order to survival. The situation in fact causes that the man must direct, through his conscience and condition of psychic subject, the actions directed to his survival. To do this, he must take charge of himself and the reality that surrounds him. He must then put into action his natural faculties and, above all, knowledge and the rational way of producing knowledge. Man has produced knowledge in various ways: in ordinary knowledge, in philosophy and in science. Since man starts from the impulse to life his knowledge is oriented to the immediate reality in which he must survive and also to the ultimate contents of the universe that contains it. Everything that is real, mainly the ultimate truth of the universe, has something to say to human hopes to reach, in reality, the fullness of life.

Reason is asking about the causes of the fact of the human universe. The man, moved by his deep aspirations for life, verifies what actually occurs to his experience and wonders about the causes that have produced it. What in fact it observes phenomenologically, as we have exposed, is, first, the real existence of a psychic world, in man himself, that allows one's own self-experience and opening to the cosmos as a world of fields of reality. It is the human insertion, in fact, in a holistic universe. But, second, it also confirms the existence of a world of objects, closed in on themselves, differentiated and distant in space-time. 
The fundamental questions refer, then, to the causes that have produced the existence of a world of fields and, at the same time, a world of objects. A reality in which objects and fields have become intertwined in the unity of cosmos.

The enigma of these two great questions, «objects» and «fields», is one of the great concerns of human reason in philosophy and science. Also in religions and their cosmological visions. As a background, these two questions are projected towards the deepest enigma, namely, the ultimate truth of reality. The truth of the universe. Ultimately it is the enigma of what is the ultimate truth towards which the fact of cosmic holism projects, which we have mentioned in the title of this article.

\section{ONTOLOGY OF MATTER, OF MAN, OF UNIVERSE EXPLAINS HUMAN EXPERIENCE OF COSMIC HOLISM}

Knowledge promoted by man in science has come to perfect the primordial phenomenological experience of man, ordinary knowledge and philosophical knowledge, to understand what is the reality that produces and contains us. More precisely, what is the ontology of reality, that is, the real mode of being of matter, of man and of the universe, to explain the causes that produce our primordial experience, of a world of «objects» and of a holistic world of «fields». This knowledge plays an essential role in rational reflection of man around the enigma of the ontology of the ultimate truth of the universe. We approach, then, the current scientific image of the universe to guide it to the way it explains cosmic holism and the existence of a universe that seems alien to holism, that is, the existence of a universe of pure objects.

\subsection{Matter}

The image of the real world produced by science begins with the idea of matter. It is a phenomenal fact that, through our senses, we have access to the experience of a world constituted by physical objects (our very body is a physical body) that are made of «something». The term «matter» designates that "something» that constitutes in depth the real ontology of things. When science names «matter» it does not designate a closed knowledge (as if it were already known finally what matter is), but the end of a process of knowledge still to be covered: something that must be known, reaching a correct representation of its ontology (of its way of being real and existing). By the proper method of science, many things of the matter have been known: but today it is still far from knowing its ultimate nature. In turn, the scientific knowledge of the universe as a system depends on prior knowledge of matter, since cosmological theories are constructed from the physics of matter.

The scientific idea of matter is decisive when it comes to understanding what is today the image of man and, above all, the image of the human psyche, of his conscience or of his «mind». As we will see, the idea of matter, in the 
framework of classical mechanics (Newton), ended up deriving what has been known, and is known, as «reductionism». This carries with it important implications in relation to the philosophical answer to the last questions about the metaphysical. However, through quantum mechanics, and the need to find a convincing scientific explanation of living beings and of man, today we have arrived at a holistic idea of matter and the universe that currently implies a favorable approach to understand the universe in a theistic way. To argue about the philosophical and metaphysical repercussions of science it is necessary to know how to understand the process and the representative logic that lead both to classical-reductionism and to the modern quantum holism of science.

Next, we recapitulate the history of the most outstanding milestones in this process of developing a scientific idea of matter. We make an observation: in the previous phenomenology it was said that the first human experience is the holism that is seen in the same psychic experience. From the psychic-holistic experience one also notices the existence of a world of objects. Here, on the other hand, we are going to begin with the scientific image of the world of objects (mechano-classical) and then move on to the scientific image of the world of fields (mechano-quantum). The reason is that the history of science began with classical mechanics and then later discovered, in the 20th century, quantum mechanics ${ }^{1}$.

\section{Classical mechanics: a differentiated world of objects}

The physics of Newton. It is the physics of the world of macroscopic objects that constitute differentiated and punctually spacetime. We observe stones, planets,

$1 \quad$ Field physics and particle physics. Knowledge of the physical world at the beginning of the 19th century confirmed the existence of two different types of "physical reality»: matter and radiation. Matter were the bodies of Newton's physics that occupied a definite and punctual place in space-time; they were constituted by mass made of a «matter» that conferred a "weight» depending on the ultimate nature of certain "atoms», whose knowledge came already from the Greeks (who had by themselves a certain "atomic weight»). The radiation was not, on the other hand, a punctual phenomenon but a «field». Radiation extended into space-time "fields» where it produced vibratory-wave effects. Three types of radiation were known: heat, electromagnetism and light (the corpuscular theory of light in Newton had already been surpassed by Thomas Young's wave in 1812). The idea that it was not about different things but about the dual manifestation of the same unitary matter did not reach the incipient quanta of energy in Plank (1903), the corpuscular-wave idea of light in Einstein (1905), its extension to the electron by De Broglie (1923) and the birth of quantum mechanics. Since the twenties we know, therefore, that there is not only a particle physics, but also a physics of fields. Both describe aspects of the same unitary corpuscular (atoms) / undulatory physical reality (fields). However, something has happened throughout the history of physics in the twentieth century when it, in certain circumstances, has been «reduced» to a physics of bodies and particles. In fact, physics applied to the explanation of the psyche has been «reductionist» (classical) and only at the end of the 20th century has it been intuited that the physics of the fields (which was already ancient and was known from the physics of radiation XIX) should also play an essential role in explaining the "physical support» of the psyche. 
celestial bodies, plants, animals, men, molecules, atoms, particles ... They are real entities "differentiated» because they are independent bodies that exert a great variety of interactions among themselves. The physics of Newton described that world by mathematical analysis and defined a complex system of variables to study it (mass, weight, force, space, time, speed, acceleration, direction, work, etc.), as well as quantitative methods to measure them and the mathematical functions that related them (for example, the formula of universal gravitation or the formulas of the physics of movement). But what are these bodies and their interactions in the Newtonian world? Where did they come from in the course of evolution?

Evolutionary genesis of the classical world. Today we know that the universe began being pure radiation; this is true, both for the big bang theory and for the speculative hypotheses proposed by superstring theory. As the radiation field cooled, the particles that would constitute the «matter» of the bodies were born. Current physics knows that corpuscles of many types emerged. Essential for us is the distinction between bosonic (Bose-Einstein) and fermionic particles (by Enrico Fermi). We will refer to the bosonic particles later. Now we deal with the so-called "fermionic» because of them the world of classical mechanics is preferentially constituted. Fermions (proton and electron are) have properties derived from their type of vibration (or wave function). An essential feature is that they tend to remain differentiated, without merging with each other or with other particles forming a common, undifferentiated and unitary vibratory field. In an atom, for example, electrons vibrate in certain orbitals (each in their space-time) without merging and maintaining independence. Although the electron in its orbital is not a corpuscle but a vibration, it remains differentiated in its orbital, without merging with other electrons that will vibrate in other differentiated orbitals. Thanks to the persistence of these particles in remaining independent there are atoms, molecules or bodies in general compact, differentiated and with differential properties. This is the world of the objects of classical mechanics: it makes us possible as independent living beings that build our history in the midst of a world of objects that are also differentiated. If there were not the type of "fermionic» matter, there would not exist the universe of independent physical objects that we know and that have made life possible.

Classic causal interaction. The interactions between fermionic particles and between classical bodies explain our macroscopic experience. By the action of the four great known forces of nature (gravitational, electromagnetic, strong nuclear and weak nuclear) particles attract or repel each other precisely, sticking together to form complex systems such as atoms, molecules, minerals, living beings or bodies in general. Two billiard balls crashing or the celestial gravitational forces of the Newtonian universe are examples of classic cause-effect interactions. Electrons - essential constituents of matter - interact by electromagnetic forces; the atoms stick and take off by means of covalent or ionic bonds. But in the classical world, cause-effect interactions occur on the border between entities that remain themselves in their differential state: the billiard ball, each electron or proton, each celestial body, each living being. The effect produced by classical causality (the four forces) sticks or detaches, attracts or repels, displaces, deforms, divides into parts, etc., but always acting on differentiated and independent entities in spacetime that do not cancel out as such. This causality is deterministic: put certain conditions 
antecedents of its physical state the effect occurs inexorably; for example, between two electrons a covalent bond will be produced or it will fall apart; a magnetic field will produce such precise effects; a force applied continuously to a mass will produce such acceleration. The field of classical causality appears, according to this, as a plot of infinite series or cause-effect chains that together produce an effect that can be illustrated in the image of a "machine». Blind and deterministic causality.

Classic reductionism. Every physicist knows that physical reality is not only fermionic particles and differentiated bodies. It all started with vibratory fields that still exist. The vibration produces corpuscles, but the corpuscles, the matter, can be undone in energy-vibration. Suffice it to recall that we live on solar radiation or the importance of electronic communication technology based on the wave physics of fields. However, there is a tendency, which we call «reductionism», to consider that in the real world everything that happens is produced as the effect of classical causal interactions. This tendency reduces the pitched explanations to the minimum (only when necessary for technology) and tries to explain the most relevant aspects of the macroscopic world through classical causal interactions, including the biological world. For physicists the so-called quantum mechanics studies microphysical phenomena: from certain microphysical dimensions everything is quantum mechanics. The electron and the proton are part of quantum mechanics. However, there is a tendency to explain the microphysical world from the model of classical macroscopic physics. The Bohr atom, for example, was conceived from the model of the solar system. There is a «classical» way of considering the microphysical particles and events in which the classic macroscopic image of a world of differentiated entities prevails between which there is only a classical causal interaction. We move then towards a «reductionism» tending to see the world from the discontinuous and deterministic image of classical physics.

Classic reductionist neurology. As we will see later, when talking about life and man, it is based on our knowledge about the neuronal world from the point of view that the brain is only a field of classical causality in the reductionist sense exposed. The light, the mechanical vibrations of the air, the gravitational fields of the Earth, the senses, the retina, the cochlea, the neurons, the axons, the nervous stimuli, are always a very complex chain of classic causes-effects. What happens, then, are causal interactions at the border between some entities and others (electrons, macromolecules, calcium ions, potassium pumps, neurotransmitters, photons, photopigments, etc.). Sometimes the causal action and its effects occur in the midst of huge amounts of events that interact chaotically (eg, in the cytoplasm of the cell). But overall, with statistical-probabilistic security, this or that deterministic effects will eventually occur. Living beings are thus chains of transmission of causeeffect interactions that leave one point and reach another ( $\mathrm{eg}$, from the retina to the terminal neural activations of the image engram). In the neuronal world effects are transmitted, but in classical mechanics one tends to forget and to investigate what happens with the fields.

\section{Quantum mechanics: a holistic world of fields}

Classical mechanical connection and quantum mechanics: physical holism. Newton's world, classical mechanics, was born much earlier than quantum 
mechanics. However, the quantum perspective has assumed the explanation of the classic-macroscopic world. This is what we have just explained: in some way (because many problems are still pending resolution) current quantum mechanics explains how fermionic particles are trapped structurally in the order of matter and bodies, producing a world of mechanical determinations and statisticalprobabilistic regularities. The tendency to explain the real world by applying only the resources of classic Newtonian causality is reductionism. But quantum mechanics has also assumed that radiation phenomena in the field, known since the nineteenth century, have constituted and continue to constitute the essential aspect of the explanation of the current universe.

Holism in quantum mechanics: bosonic matter. As we said, the universe probably occurred from a germinal radiation (in the form of strings or superstrings, if this speculative theory turns out to be correct). The constituent substrate of physical reality oscillates between corpuscularity and undulation in a physical field. How to understand that fundamental reference background (and the description of its physical ontology) in which the genesis or dissolution of vibrations or corpuscles takes place has not been or is not entirely clear in physical science: quantum vacuum, energy field, ether, relativistic space-time, implicate order (Bohm), etc. In any case, the process of corpuscularization (or folding of the energy in corpuscles) initiated in the big bang seems that it did not lead only to the birth of fermionic particles (which ended up trapped in the macroscopic matter). Another type of particle called bosonic was also produced (by the discovery of the "Bose-Einstein condensate» in the 1920s). Bosons can also get trapped in fermionic matter, but they can have physical realms where free existence is possible. But bosons (eg, the photon, light) have a wave function that makes it easier for them to lose their individuality (unlike fermions) by forming similar states of undifferentiated unitary vibration with other particles that fill certain bounded spaces. The bosonic matter tends to constitute, then, holistic states or fields of vibration of undifferentiated matter. In the current universe not only stable matter produced by fermions exists, but there are also niches or bounded physical areas where holistic effects are produced within a classical world differentiated from isolated entities of fermionic matter.

Quantum coherence. This important concept of quantum mechanics is closely related to the equivalence of matter-energy, corpuscle-wave, discontinuitycontinuity, locality / non-locality. The bidirectional conversion between each of these two aspects of the substrate that constitutes the universe explains the birth of bodies from the big bang (direction energy to corpuscle) and the conversion of matter into physical field or energy (direction corpuscle to field). The state of «quantum coherence» designates that physical situation in which the particles lose their individuality entering into pitched states of undifferentiated unitary vibration in defined space-times. It is what was discovered already in the Bose-Einstein condensates. Today there are countless evidences of these states in varied physical contexts. Apparently the property of entering quantum coherence is typical of all corpuscles (it is known that under extreme experimental conditions electrons also enter into quantum coherence), although fermions present greater difficulty for this, given the physical properties and the wave function of the fermionic particles. The process in which a system loses its quantum coherence and is reduced to 
individual particles is what is known as the "quantum de-coherence» process. Hence, producing or maintaining processes of quantum coherence is not easy, even with bosonic particles, since the interaction with the classical macroscopic world interferes and induces the de-coherence that continuously leads to these particles also being trapped in the ordered rigidity of the classic world.

Action at a distance and non-locality: EPR effects. The famous imaginary experiment of Einstein, Poldolski and Rosen in 1935, being already Einstein in Princeton, allowed to conceive imaginatively that the idea of matter in quantum mechanics allowed the existence of a new type of causality (which seemed inadmissible for classical mechanics): non-local or action-to-distance causation. The change in a particle could cause a corresponding change in another particle correlated with it to millions of light years, without transmission of a causal action at a distance, that is, without local presence (non-local causality). These facts, verified in 1982 by Aspect, and repeatedly replicated since then in a great variety of experiments, have opened a new perspective in the knowledge of the interactions between matter. Different areas of matter in quantum coherence, for example, at a distance and without local contact, could nevertheless enter into interaction as part of unitary systems, extended in space-time discontinuously.

States of quantum superposition. This new property known in quantum mechanics affects all types of matter, fermionic or bosonic; although the latter, because it is more free and oscillating, may have a greater ontological facility to be in states of superposition. Superposition means that the same particle, or a quantum state, can be indeterminate, that is, as floating without definition in relation to different values of a variable or property of that system: for this reason it is said that a system in superposition is at the same time in many states (because they are possible) and in none (because it has not been committed to any). When, for example, an overlapping particle is made by «choosing» one of its possible states, the «collapse» of the wave function of that particle occurs. Thus an electron, for example, is in its orbital vibrating in a state of superposition, in such a way that when it is corpuscularized in a defined position the collapse of its wave function has occurred. A system in quantum coherence could also be in a state of superposition, producing in certain circumstances its collapse in a specific vibration of the whole system.

Quantum indetermination. It is known that, faced with the classic causality of a completely deterministic process, quantum mechanics considered it necessary to introduce the hypothesis of the indetermination of quantum events. After Schödinger proposed his famous equation to describe the position of the electron, two other mathematically equivalent systems were proposed, the matrix mechanics of Heisenberg and the algebra of Dirac. But in any of the formalizations of the quantum world it is counted on that the events present a scope of indetermination that makes them unpredictable. Not only because the experimenter enters the microphysical world to measure and produces uncertainty about future events, but because the same interaction between particles at quantum levels produces effects of uncertainty about their future behavior (Heisenberg uncertainty principle). Not only the future behavior of a particle becomes unpredictable, but formulas to predict the course of interactions or microphysical reactions, when talking about large 
amounts of events, can only be done through statistical and probabilistic techniques. To this is added the same fact of the quantum superposition that presents serious difficulties when it comes to predicting in a deterministic way when and why the collapse of the wave function towards a specific state will occur. The discussion on how to interpret indeterminacy in quantum mechanics has filled the twentieth century and is still open. The way of relating the determinism of the Schrödinger equation to quantum indeterminacy, the eventuality that indetermination was really ontological (given in the microphysical reality itself), the eventuality that it was only epistemological (a deficit of knowledge that required only cognitive or functionalist resource the use of probability and statistics, as the School of Copenhagen de Bohr thinks), or the possibility that there were hidden variables in such a way that the microphysical world responded to the deterministic image of the classic macroscopic world (Einstein, Bohm), are just some of the profiles of the problem posed by quantum indeterminism.

Holistic quantum neurology. In principle, it is a heuristic hypothesis: a way of understanding to what properties the type of "physical support» that has made possible the evolutionary emergence of sensitivity-consciousness could respond. Classical neurology (engram theory), opted for the hypothesis that the interactive chains of classical causality were enough to explain the psyche. However, it fell into reductionism because of the freedom, indetermination, the spontaneous choice that occurs both in the animal and human world (what the Anglo-Saxons call the choise) and the phenomenological field experience given in the psyche (Gibson's direct perception) can hardly be explained by the classical physics of a differentiated, discontinuous world, with a blind, deterministic and mechanical causality. Quantum neurology, as opposed to classical, is simply the heuristic way that contemplates that psychic properties could have their "physical support» in the properties of the quantum world: first of all in quantum coherence, distance action and non-local causality, the quantum superposition and the indetermination. It is, then, a defined search program: first of all those psycho-biophysical structures, which should be rooted in the neuronal system, which in living beings were the support of «niches» or quantum-state spheres in which the described properties could be that could be connected with the explanation of the psyche (hypothesis Von Neumann / Stapp). This task is not easy since the initial biophysical description of living organisms and their nervous systems show a compact world of classical interactions that reductionism inevitably seems to impose. Quantum neurology is the attempt not to reduce the explanation of the psychism to the classical, leaving hypotheses that open us to a quantum world, as legitimate in physical science as the classical, since in principle it is intuited that between the properties of psychism and the properties of the quantum world seem to exist striking parallels.

\section{The theory of strings and superstrings}

Beyond the Age of Planck. There is also the persuasion that what is produced in the macrophysical and in the microscopic is in agreement with four basic forces of nature known as gravitational, electromagnetic, strong nuclear and weak nuclear. The gravitational force is essential to explain the macroscopic (both the structure 
of the universe and the interactions between macroscopic bodies). The other three forces explain quantum events and physical fields. Physical science considers two obvious assumptions: a) that matter, at the time of its germinal birth, should have properties and a primordial nature that makes us intelligible how and why the microscopic world of particles or bosonic states and the world macroscopic of stable objects according to the visible structure of the universo will be produced. It would be a primitive world, prior to the parallel diversification of the classicmacroscopic world and the quantum-microscopic world. That world should explain how and why the properties of matter germinally produce electromagnetic, strong and weak nuclear forces, but also how the force of gravity is born and acts in the quantum world. The lack of this theory of quantum gravity is responsible for classical-relativist mechanics and quantum mechanics to run in parallel without knowing the common trunk from which they are derived. That world previous to ours, in which the quantum world would not have been differentiated from the classic-relativist world, is known by physicists as the physical reality beyond the Planck Era.

String theory, later reformulated as "superstrings,» is a complex conjecture about what matter could be at its primordial origin. The essence of the theory is that matter would respond to very small entities of a vibratory nature (small vibrating strings), of very small size (about 100,000 times smaller than the smallest object known in the "standard theory of particles»). An initial theory had to be conceived that presented a variety of cords able to generate later the variety of natural forces (including the germ of the gravitational force) and of all the variety of particles, as well as the particle-wave duality of all matter. To do so, the string theory conceived that the strings had a value in nine dimensions (strings) that were later extended to eleven (superstrings). In a simple way we would say that, just as in a three-dimensional space, the punctuation in each of the axes distinguishes one point from another, so also the position of the superstrings in eleven dimensions would allow us to describe the own ontology of each one. To conceive how these multidimensional cords could generate our real world, it has been necessary to speculate with a multitude of physical and mathematical models that have been worked on in university research by thousands and thousands of researchers.

However, it has not been possible until now to collect the slightest empirical or experimental evidence that supports string theory. Moreover, it is even thought that by its nature it could never be object of empirical testing. On the other hand, there are theoretical alternatives to how the ontology of matter would have to be conceived beyond the Planck Era, at a time before the birth of the classical and quantum worlds today. We can remember the non-commutative geometry alluded to by Michael Heller, the recent Templeton prize, or Penrose's theory of twistors. In any case, string theory is increasingly subject to severe criticism, such as that of Lee Smolin, and more and more people are questioning whether it would have been useful to have devoted so many hours of speculation to its theoretical development.

Conclusion. We said, at the beginning of this article with some considerations about phenomenology, that man starts from the given experience of being immersed in a world of «objects» and a world of «fields». Man is also in the 
self-experience of his reason. He wonders why are the causes that make this world of «objects» and «fields» possible. Science, constructed by man, has explained the causes of that field world, quantum mechanics, and the causes of that world of objects, classical mechanics. The coordination of these two mechanics, classical and quantum, also explains human nature, in harmony with the classical / quantum universe.

\subsection{Man}

\section{The scientific image of life and man}

Unquestionable empirical evidence is that the evolution of the universe produced the appearance of living beings. It is, therefore, obvious that science must explain why and how they appeared. That is, it must know the causes that led to their evolutionary genesis. Science, therefore, must explain the causes of what living beings are in our immediate experience. The unquestionable empirical evidence is that life is as we warned: living beings are psycho-biophysical entities. Physical because they are part of the physical world. Bio because they are special physical entities: they are bodies organized in a more complex way than pure non-living physical entities, presenting new properties (reproduction, variability, adaptation, etc.). Psycho because they present a psyche that, from the sensation-perception-consciousness, produces the activity of animal mind and of our human mind.

The basic assumption of science is that the psycho-bio-physical entity of living beings has been produced from the properties of the physical world, that is, from the matter that constitutes it. Is there any other alternative? Not seem. For about ten billion years there was only a physical universe and life emerged from the structures of the physical world. Life, therefore, can only be a special, though more complex, form of organization of the physical world. Now, if at a certain moment the psychic properties also emerged, they could not have been produced either if the biophysical world had not the capacity to produce them from the primitive ontology of matter.

\section{Life and animal mind}

1) The origin of the living body. There is no doubt that our life depends on our having a stable biophysical body that allows us to have a mind, undertake actions, build our own biography and maintain our identity in the course of time. But our body is part of the classical world and is subject to an enormous amount of pure deterministic and mechanical interactions. All organ systems and the brain itself function largely by deterministic and mechanical causal interactions (for example, chemical-electrical signals via the synaptic pathway). The fact that biophysics and biochemistry are forms of the specific organization of living beings does not mean that they are not «physical». We have a greater complexity, emerged evolutionarily from the genetic codes, which with 
deterministic security guarantee a high reliability in the transmission of the inheritance to the species. The current biological science, in harmony with the physical-chemical paradigms, explains the origin of all the contents of biological complexity: genetics, embryogenesis and the neural mechanisms of the brain.

2) The origin of the psyche and of the mind. Science must also explain something that is presented as undeniable empirical evidence: the fact of the psychism, animal and human, evolved from the emergence of the sensitivityperception-consciousness and the fact of the psychic subject, which appear in the course of the zoological scale. What are the causes of the psyche? Science can only address one answer from two epistemological assumptions. A) It must first describe the phenomenological properties of the psyche, which must be explained (explicandum). Thus, the feeling-of-field, the indetermination and the controlling causality of the body that culminates in the action of the subject that controls the body in a holistic manner are verified. In man, moreover, rationality, freedom and responsibility of the psychic subject (or human person) are specifically verified. B) The causes of which this type of entities are real, with all these psychic properties, must be investigated by science (finding an explicans). It has already been said that the essential assumption of science, to look for the causal system of the psyche, is that radical causes must be in the ontology of the physical world (physical support of the psyche).

3) Reductionism. So, can the causal system of the psyche be reduced only to classical deterministic, mechanical interactions between differentiated, isolated and discontinuous entities? The fact is that classical mechanics could not explain most of the properties of psychism (let's say, at least, that it is very difficult to do so). Therefore, reductionism caused the recurrence to dualism, given the convincing impossibility of explaining in a monist frame the physical and the psychic, only founded in classical mechanics, without this explanatory way not going to underestimate the psychic properties, reduced to robotic (as seen in modern computational reductionism).

\section{Life and quantum properties of matter}

4) The classical-quantum explanation. It could not be doubted that living beings, as psycho-bio-physical entities, are largely classic entities that respond to the type of classical deterministic interactions (the biological body). However, in the current human sciences an obvious fact has been found: that those psychic properties that are not explained by classical mechanics, have an extraordinary similarity with the strange properties of the quantum world: the quantum coherence in connection with the psychic experience of a fieldof-reality; the quantum superposition and indeterminacy in relation to the real experience of indetermination, freedom and the causal action of the living subject; the action-at-a-distance to understand both the field experience and the holism of the psycho-bio-physical systems. Hence, the quantum hypothesis to explain the causes of psychism establish that living beings are not only classical 
deterministic systems, but also must contain certain «quantum niches» in which those «strange» properties of matter could be realized in quantum primordial matter (not yet trapped in the rigidity of the classical deterministic structures), which would constitute the appropriate "physical support» of the «strange» properties actually present in the psyche. In this way living beings would be causally explained by a balanced classical-quantum system: the classical body (stability, identity) and the quantum niches (field-of-reality, indeterminacy), both coordinated by an evolutionary design.

5) The Hameroff-Penrose hypothesis. The general hypothesis about the causes of psychism in "quantum niches» (Von Neumann-Stapp hypothesis) leaves open a basic question: where and how are the «quantum niches» proposed by the von Neumann-Stapp hypothesis implemented? It is an open question. But at present the so-called Hameroff-Penrose hypothesis is the most notorious, and controversial, answer to this question. It argues that, in the microtubules, distributed along the cytoskeleton of every cell, and neurons, those requirements would be fulfilled enough to implement the «quantum niches» that could explain the properties of the psyche. Between microtubules (in a neuron and in systems of neurons, networks or engrams) would be established, by action-at-adistance, systemic states of quantum coherence and in a state of superposition. These states would be collapsed to one or other activations by impulse of the psychic subject that would thus causally control the brain and the actions of the body in one or the other direction. In this sense, the explanation of the causal system of living beings would be classical-quantum. A classical body, subjected to the classical deterministic interactions in its internal processes, and in its relation to the external environment, and some quantum niches interspersed in the classical body and connected to external physical fields of a quantum nature (for example, light in the fields of vision).

6) The evolutionary explanation of the animal mind. The first cells were with almost complete safety purely classical deterministic systems (as in us is still the embryogenetic determinism governed biochemically by the genetic code). Sensitivity probably emerged at an advanced stage of the evolution of unicellular living beings (from the microtubules of the cytoskeleton, if the Hameroff-Penrose hypothesis were correct). In the multicellular animals, a nervous system was specialized to organize the internal and external sensation, and to use it as an information system to respond effectively to the environment. In the stimulation-response connection, the psychic subject gradually emerged. The sensations in the different senses were transmitted to the central nervous system (brain) where the activation of engrams (or systems of interactive neurons by classical synaptic pathway and, perhaps, with its consequent quantum effects on microtubules) occurred. The activation of these engrams (or patterns, maps or neural networks) had as a psychic effect the correlate of sensations (sensitive images) that began to be registered throughout the brain (from the ancient brain to the modern cortex). When the cortex appeared in mammals, memory mechanisms were perfected to record and connect the 
various engrams between neural links and order them in the mind, facilitating their recovery. The animal then begins to respond to the environment based on the remembered present, according to Edelman's proposal. The animal thus begins to act not only in terms of what is felt in real time, but also in terms of other memory contents that are present when activated by the network of links that connect them. Through this combination of images, the present and the past, the animal begins to form "representative packages», produces abstractions, is able to categorize, perform primitive logical functions, anticipate the future and have behavioral plans. All this without the rupture of the signitive or instinctive, automatic character that still dominates knowledge and animal behavior has still occurred.

\section{The evolutionary origin of human mind}

7) The evolutionary explanation of human mind. Hominization is the evolutionary transition from animal knowledge-behavior to human knowledgebehavior. The point of inflection between the animal and the human is the emergence of reason. It is also clear that reason produced a new emotional world. Therefore, we could say that the inflection occurred in the emergence of emotional reason. Now, what are the causes of the evolutionary emergence of reason and what is its nature? Which is reason? Within the emergentist theory, according to the theory of engrams or neural networks, a set of causes that probably produced the emergence of reason can be established: the biological unspecialization (A. Gehlen); work (Luria, Marxist neurology); the socialization-language in the animal group (Eccles, Tobias, Richard Leakey); the complexity of the protohuman behaviors that appeared in the animal world (K. Lorenz, the biology of the knowledge of his disciple Rupert Riedl); or, the theory of Xavier Zubiri that establishes that the cause of the hominization was the hyperformalization produced in the animal nervous system (which thus became human). These five theories are harmonious and congruent with each other to explain the system-of-causes that produced hominization, that is, the evolutionary birth of reason.

The theory of the hyperformalization of Xavier Zubiri would make the hypothesis that the specific state of the human nervous system (hyperformalization) would have produced: a) to feel the stimuli not only as pure stimuli, but as «realities», b) in such a way that this new «look» towards real things in themselves would have made man realize that they are «real» as «structures», c) leading all this to the emergence of a new function of the mind, the reason, that by means of the analysis and mental synthesis of the real structures, would take to form in depth rational representations of the world. Through this search for the founding roots of reality, the human mind would have been open to rational knowledge, to science and to metaphysics. That the human psyche was capable of producing this transition to reason is also explained by the state of psychic hypercomplexity already produced in higher animal species, especially in hominids. The abstraction, the categorization, 
the basic logical inferences, the imagination, the anticipation of the future..., were all functions of the animal mind that, without a doubt, made possible the evolutionary transition to the new "human representation of reality». To all this, I have referred extensively in other writings.

8) History is explained as a product of human mind. We have just seen how the nature of human mind and reason within the framework of current science are explained. It is much more difficult to explain how and why the capacity to «feel» (even in unicellular animals) has emerged, than to explain, already assumed the evolutionary existence of the universe and the emergence in its interior of the "sensible life», the causes and processes that could lead to hominization, that is, to the emergence of emotional reason. We have offered, then, a possible hypothetical scientific explanation of the origin and nature of rational mind. Any other alternative explanation would also be a hypothesis.

Do we need something else to explain the causes of what man has done in history? We do not believe it. Man, very similar to the animal mind, but already as a rational mind, is born with an organization of its sensory systems, internal and external, with buses (connection routes) with the upper nervous system (normal organization of the species that can be remodeled to surprising ends by the cerebral plasticity). As he lives, man configures in his mind a huge amount of engrams or mapping that, when activated, produce that the psychic subject feels in real time or remember by memory. The animal brain, only sensorymotor, has been completed by knowledge and by thought that interprets, by the reason, the sensible world.

Thus, both knowledge and interpretation of the world are recorded in engrams of frontal and prefrontal zones (specific to the human species). In language the human species has found a superior instrument to know, describe and think about the world. Man knows and thinks not only through sensitive images, but also through language. A huge amount of neural records (engrams) are located in the brain, mapping it, in relation to the sensory-imaginative, knowledge, creative-interpretative thinking and language. Each personal biography supposes a personal mapping of the brain. At the same time, the world of knowledge and the world of actions, both in the same representativemotor system, are linked by a dense web of links to the emotional brain that connects with the determining "value» of «life». Man — namely, his «I», his sensory, cognitive, imaginative, representative, motor, emotional systems- is nothing else than the complex network of neural engrams of his mind built in his mind. When the network fails, as it does in old age and in degenerative diseases of the nervous system, its individual personality falls dramatically and the «biographical self» disappears. It is an unquestionable fact.

Human thought, religions, social organizations, culture, science, philosophy, emotions, literature and poetry, art and all forms of the human imagination, history in all its manifestations, are a product of the neural activity of the mind, as we have described. It is not, therefore, that man is not the man of poetry, of art, of literature, the man of all the finest manifestations of his sensibility. But what 
we know today is that this man is capable of producing all these manifestations of his psychic life from the neural activity of his brain. It is true what is said today: scientifically, man is his brain. This is what science tells us today.

Therefore, the scientific explanation of man in the evolutionary framework of a monist universe tells us that everything was born from the material substrate that constitutes the background of physical reality. What is that universal fund? We do not know with total security, although we have come to know many things. Here we have exposed them. What the scientific-philosophical image of man today excludes is dualism in all its variants. We assume, then, the anthropological monism and it is supposed in everything that we should say throughout this essay.

9) Neurology of religion. We can illustrate this with a brief reference to religion. The human brain has been shaped by adaptation to the environment and its evolution is not closed, it is open and plastic. The real physical world is thus a world of objects (stones, trees, cliffs...) and therefore the system of senses has evolved to make animals feel that world of objects (thus, in the visual image, in some way isomorphic with the world). Now, when reason emerged, aspects were added to a rational configuration of the brain that did not exist before. Everything seems to indicate that prehistoric men began to exercise reason and the experience of the universe, together with the impulse to achieve the fullness of life, oriented their rational imagination towards philosophy and metaphysics. The religious also appeared there. These metaphysical references have been so constant in the human species that have made a hole in the neural structures.

Therefore, nowadays it is known that these engrams are in the inner part of the temporal cortex and extend to the prefrontal zones. In addition, a dense web of links connects these cognitive engrams with the emotional zones of the limbic system (the amygdala). Therefore, the idea of God produces profound mystical emotions that seem to unite the individual with the All, with the cosmos, with an enveloping and holistic Divinity, as empirically described in clinical phenomenology (neuro-theology). This fact does not show that God exists or does not exist, but it does show that religion is possible because the brain functions by engrams and there are specific neural locations that support the religious experience. The religious brain was built from primitive man. It could not have been otherwise, given what we know about the brain and the human mind ${ }^{2}$.

\footnotetext{
2 Christianity, at least in the form of Catholic theology for centuries, was always dualistic, according to Platonic-Aristotelian anthropology. It may seem strange that here we say that modern science today offers a monistic image of the universe and the human constitution. Is monism congruent with a Christian image of man? What is the essential content that must be maintained in a Christian anthropology? The man who describes the Bible, from which the Christian world is born, is a natural man, born in the monistic evolution of the universe. The Bible describes, from the Old Testament, and with greater force in the New Testament, how that natural man is affected by an internal call from God: from the Spirit of God in his natural spirit of man. Faith is the answer to that call of God that appears in history. That call
} 


\subsection{Universe}

In cosmology, science arrives at its argumentative limits, at the last questions, but in it unavoidable philosophical uncertainties remain. In the knowledge of matter, of man and of the cosmos, in its intrinsic physical connection, is where science is projected principally and basically on philosophy. On the last questions. The man who, in fact, is in the phenomenological experience of himself, from his psychic experience and his reason, is known in a world of objects and fields. As a result of the analysis of reason in science man knows today what are the causes of that world of objects and fields. Science tells us that the universe is mechano-quantum, in depth, but the quantum world, in evolution has come to produce the world of objects that science knows as mechano-classical. But the search for rational knowledge does not end here, although it must pass through the knowledge of the subject. The great questions about the ultimate truth of the universe remain open, since, from that ultimate truth, the possibility of reaching the Life to which man aspires would depend.

For science, proposing conjectures about this enigmatic universe, it shows that its ultimate and absolute Truth is not patent. It is an enigmatic universe that makes it possible to construct a metaphysical hypothesis of a purely mundane character, atheist, without God, and another theistic metaphysical hypothesis in which God is posited as the transcendent foundation of the being of the universe. Science constructs this enigmatic idea of the universe from the results of the scientific idea of matter, namely, from classical mechanics and quantum mechanics.

The expectation of science is that the universe can be understood as a consistent and stable system that maintains itself with sufficiency. It is at the bottom of Parmenides' intuition: if there is a universe, it is because it can exist; otherwise, it would no longer exist. Therefore, if in fact the universe is there and exists, it is because it is founded on an absolute and ultimate sufficiency. How to understand it? In principle, sufficiency seems to ask to postulate the eternity of the universe; since, if at any time it did not exist, how understand the transit from nothing to being? Newton and Einstein had the expectation of a stable universe and therefore understood it, in effect, as eternal. In the universe, the ontology of an objectual world and a world of fields coincide. But the results of science, now subject to philosophical reflection, suggest that the universe is ultimately a holistic reality, that it could be God, but that it could also not be.

moves confidence in a saving God, liberator of death. Faith is, then, trust in the power and fidelity of a God who will respond to the end in what that call promises. Man knows that he is mortal (in the evolution of a monistic universe), but he trusts that God who mysteriously calls him. Trust that his power can save him beyond death. Trust that God will save his personal reality, his personal history and his biography, his "I», beyond death. Trust in a personal survival beyond death is not, therefore, a consequence of the dualist persuasion that in man there is something that, by its own ontology, "could not die», is "immortal» (unfeasible persuasion since modern science), but the trust of that God who calls and who promises salvation beyond death. 


\section{Basic gravitational theories}

The gravitational universe of Newton. This way of conceiving the universe was an almost inevitable consequence of Newtonian mechanics, founded on the law of universal gravitation. Newton conceived a gravitational universe extended infinitely in space, in such a way that the gravitational force coming from all its corners was compensated and each celestial body crossed its orbits with mathematical precision. This universe of clockwork, however, was not conceivable without God because He was the creator of his rational order and because without punctual interventions of the provident God the stability of this order could not be maintained eternally (remember the problem of the tangential forces introduced by Newton). This gravitational universe "floated» in a background ether that was for Newton as the sensorium divinitatis. God was, then, for Newton, present ontologically as the background of the reality of the universe. The objections that were proposed to this model of the universe during the XVIII-XIX century gradually undermined its credibility, and finally it was replaced by Einstein's universe.

The first relativistic universe of Einstein. Just as Newton proposed a gravitational universe, so the Einstein universe was gravitational. But it is understood from a new theory of gravity, based on the mechanical theory of special relativity, generalized to the universe as general relativity. The universe of Einstein is also eternal, sufficient and stable in itself. It is not infinite (Newton) but finite, although undefined and without limits. An object that circulated inside would follow the structure of Einstein's curved space and by gravity would inevitably follow those "guides» without ever reaching the end. Einstein's basic idea was to identify gravity with the curvature of space-time. Einstein conceived that, consequently, between the structure of space-time (gravitational curvature) and the distribution of matter (cause of gravity) in the universe there must be a relationship. The so-called Einstein field equations are the mathematical formulation (in one or ten differential equations) of the relationship between the structure-curvature of space-time and the distribution of matter. The resolution of these equations for local situations in the universe allows us to understand where the gravitational curves go and where the matter that produces them is. Resolving these equations in local situations predicted the existence of numerous cosmic objects and black holes. Einstein made the mistake of correcting what these equations seemed to say for themselves to maintain a stable (not expansive) universe. The facts - according to the ideas of the Belgian abbot Lemaitre- forced him later to acknowledge his error. The universe of Einstein was eternal and stable in itself, responding to a portentous rational order. The need to recognize this rational order and to attribute a sufficient cause is what moved Einstein to defend a more or less indefinite rationalistic and aesthetic theism, whose interpretation has been the subject of numerous disputes.

\section{The "Big Bang» theory and its alternatives}

The expansion of the universe and its theorization in the big bang. The theory that Einstein had built came into crisis when Hubble discovered in Mount Palomar the redshift of the light coming from the stars through his spectrography analysis. The universe that was discovered was expanding, with a centrifugal dynamism 
that separated the galaxies from each other at very high speeds. If, based on this expansion, the past states of the universe were reconstructed, we came to a first state that was called the big bang: an immense explosion of energy in expansive radiation that already contained the total energy of the universe, transformed in the course of time. Science only managed to establish some properties of that germinal explosion and its evolution in very short portions of time later. But science had no known empirical evidence that would allow us to hypothesize what was before the big bang. The proofs of this theory, especially the residual existence of the so-called background radiation, have been confirmed at present with the recent records taken by the satellite COBE. It is a theory accepted by most scientists and is the essential element of the so-called «standard cosmological model». The big bang has been completed with the assumption of great inflation: it would be a second big explosion (inflation) that shortly after the big bang would have made the volume of the universe suddenly increase fifty times. This «inflation» would explain certain properties of the homogeneous distribution of matter in the current universe. A type of universe thus conceived easily induced the philosophical question about what was before the big bang. It was evident that theistic thinkers were going to try to identify the birth of the universe with the moment of creation. This explains that soon alternatives to the big bang model appeared, especially to avoid the theism that seemed to suggest.

The theory of the steady state. This theory emerged in the fifties, initially linked to the names of Hoyle, Bond and Goldi, conceived a cosmos in continuous expansion and an internal creation of matter that maintained its relative density and homogeneous in all its regions. This expansion should be conceived as if we were painting points on a globe (the galaxies) and when inflating it, the points would be separated and new points would appear between them to maintain their relative density (the surface of the balloon is two-dimensional and therefore this image would have to be transposed) to three dimensions). Looking at this cosmos from one point would give the impression of expansion, in the way it is checked from Hubble. But this universe would remain that way forever, without the need to postulate the existence of a big bang. This theory was surpassed by the evidence and evidence about the big bang, but still has passionate followers (such as Ralph Arp). Nowadays it is related to the theory of the "plasma universe» and the evidence of the inexplicable appearance of quasars in certain galaxies is explained, inexplicable in their opinion if they are not attributed to have arisen by the creation of matter postulated in this theory. Arp and other followers of this theory accuse the majority followers of the big bang theory of having established a system of exclusion and scientific marginalization of universities for those who do not follow the official theory. Something similar to what has happened in recent years with string theory, also imposed as "politically correct», as reported by Leo Smolin.

The oscillating universe of Hawking: from the «big bang» to the "big crunch». This theory does not deny the existence of the big bang, but it is said that after a time of expansion there is a braking that inverts the time line towards a progressive concentration or big crunch that would end in a «singularity» (state of maximum concentration). in which the physical laws of known space-time could not be applied) that would result in a new big bang. Throughout the cosmic time different 
movements of concentration and expansion, of big bang and big crunch, separated by «singularities» would happen. In this way it would be an oscillating and eternal universe. Stephen Hawking, annoyed with the theistic derivations of the big bang theory towards a postulation of creation, conceived a mathematical model that would describe this oscillating universe. However, a theoretical formalization is not proof that there is something real that responds to this formalization. And the empirical evidence rather led to the conclusion that the oscillating universe was not possible. First, because the critical mass (that minimum mass that the universe should have to think that the gravitational force attached to that mass produced an inversion of the time line towards concentration) was far from approaching the required amount (it was limited to a ten or fifteen percent of the critical mass). It is evident that the mass calculation in the universe depends on many factors (mass attribution, or not, to certain particles, eg neutrinos, dark matter, dark energy, black holes, etc.), but the current calculations are still very much away from the necessary critical mass. Second, because considerations about an eternal process of expansion-concentration make it difficult to think that the oscillation could be maintained in a stable manner without degenerating; and this would ruin the process. The oscillating model of Hawking is a possible speculation, but there are not enough evidences or theoretical arguments that induce us to admit that it describes the only really existing universe.

\section{Multiverses, quantum cosmology and complexity}

Multiverses. The «steady state» and the "oscillating universe» move in the assumption of the existence of a single universe. However, the hypothesis of the so-called multi-universes or of the "bubble universes» establishes the assumption of the existence of an infinity of parallel universes and without relation between them. Where would they have come from? What would have produced them? It is evident that it is not admissible to say that they come from nothing. Therefore, the theory of multiverses supposes the existence of something like a «metareality» that would produce infinite big bangs, each of which would be the origin of a different universe. After a development in expansive time, these universes would be diluted in an energetic death. Each universe would be finite, limited in time, but its existence would depend on another reality (metareality or metauniverse) to which eternity would be attributed and an ontology capable of generating infinite universes (this metareality would be, say, being stable and eternal, which is and remains in his being, postulated by the metaphysics of Parmenides). But what ontology should we attribute to that metareality?

Quantum cosmology: the quantum vacuum and superstrings. The theoretical basis of the multiuniverses is found in the principles of the microphysical theory of matter in quantum mechanics. Newton's classical mechanics, seeing the universe as a set of differentiated particles grouped in matter, was forced to consider the existence of the ether (a cosmic substance in the background that encompassed everything in which the gravitational force was transmitted). 
Einstein's relativity, after the Michelson-Morley experiment, rejected the ether hypothesis. But the idea has constantly resurfaced (eg in Schoedinger, to conceive it as a physical support of the fields and wave phenomena of the particles). The speculation of David Bohm also supposed the existence of a holistic background of reality that he called «implicit order» (related to the nature of consciousness). The theory of relativity also did not explain clearly how to understand the existence of the "geometric structure» of spacetime understood as something real. Quantum mechanics, on the other hand, founded on different theoretical considerations and demands (eg the creation and annihilation of particles) has built the hypothesis of the existence of the entity called "quantum vacuum», energy fund, to which they would attribute those properties necessary to explain the quantum phenomena that induce to introduce this concept. In this way the entire physical world, both the corpuscular and the wave, would have emerged (or would be «reabsorbed») in a holistic background of reality. In this sense, the assumption of the quantum vacuum would explain the origin of the universe as a "fluctuation" in that quantum vacuum, with an emergency of the energy necessary to generate the subsequent evolutionary dynamics of the universe. The theory of multiverses could suppose that the concept of quantum vacuum could introduce to us in the nature of that metareality from which infinite universes would arise from infinite fluctuations in the emptiness.

If this initial energy fluctuation had produced the emergence of matter in the form of superstrings (according to the assumptions of superstring theory), each of the universes could respond, at random, to a certain set of differentiated values (relative to the eleven dimensions necessary to describe the strings). One could even calculate the immense number of possible universes that, repeating themselves, would give rise to infinite universes. There would then be an infinite series of different universes, derived from the set of values that, germinally, they would have assumed, by the very chance of fluctuation, each one of them.

Cosmic complexity: rational order and anthropic principle. In principle, the ability to generate order and complexity in the organization of the material will depend on the initial values and properties of the material. If only one universe existed, the ontological properties of that single matter would explain the order we see. If there were infinite universes, the capacity to produce order in each of them would depend, instead, on the set of values that by chance the matter arising from a «singular» fluctuation of the quantum vacuum would have assumed. There could be universes with more or less order, and even universes that do not overcome a generalized state of plasma. Now, what would the order itself be and what could be the cause of its complexity? The obvious scientific hypothesis is to attribute it to the relational fitness and repetitive combination of matter according to its initial ontological properties. Thus, a very simple ontology (a way of being initial), generating combinations in a repetitive way, could generate a very complex order (in the same way that a very simple mathematical relationship can generate an extremely complex fractal order). 
This ability to generate order and a Darwinian principle of natural selection could explain the evolutionary survival of more stable orders and the growth of complexity.

However, in the explanation of the complexity of this evolutionary order, science has confirmed the fact that, at certain crucial moments, at the "crossroads» of the process, different possible routes and values could have been followed by chance. certain variables could have responded to certain scores within a range of possibilities. That is to say, among a possible range of oscillations in the generation of order, evolution has in fact chosen only those evolutionary pathways and variable scores that, in the medium term, could conclude in the biological order and, in the long term, in the order that makes human life possible. For this reason, science has introduced a new concept, the "anthropic principle», to verify that the evolutionary order - from a set of open and non-excludable possibilities - has selected the order that led to life and man. The order created by the universe is, therefore, in fact, an «anthropic order». This pure observation of the anthropic principle in "weak sense» (without explaining its cause) is today an evidence of science that is beyond doubt.

The question that science must ask is clear: what is the cause of the existence of a verifiable anthropic order in the evolution of the universe? If the universe were unique, it is difficult to find a cause for the surprising anthropic order. One of the possibilities would be to attribute a «rational design» to the universe. In the theory of multiverses (in its case completed with the superstring theory) the surprising properties of the anthropic order of our universe could be attributed to chance (in an infinity of universes one has resulted by chance with those properties that make it possible for us). It would have produced something like a natural selection of universes, a kind of cosmological Darwinism, until the appearance by chance of the amazing universe that makes man possible.

The standard cosmological model. As we see, modern cosmology has been built on an immense amount of speculation. We believe that speculation is necessary and essential in science. At least, it always opens perspectives: it makes us glimpse that things «could be» in a certain way. But it can never forget that science is, from its epistemological foundations, knowledge based on empirical facts. It is the construction of knowledge that facts allow us to establish. In this sense, science prevents us from mistaking qualitative speculations (speculative concepts such as multiverses) or mathematics (speculative mathematical models such as string theory) with existing reality. That what is said by science must be identified with reality (not dogmatically, but critically, in the Popperian sense) can only be based on empirical evidence. Science is a vision of the world based on empirical facts and, therefore, although the speculation is legitimate, empirical theories always prevail.

Well, scientific cosmology has built the so-called «standard cosmological model» to deal with an image of the universe, its origin and its evolution over time, which responds in a minimally speculative way to scientific evidence controlled 
by the scientific community. It would be, then, a way to prevent ourselves from speculation, to offer us a criterion of how to define what we can think of as real of what constitutes speculation. An image of the universe constructed on the hypothesis of the big bang and its probable subsequent inflation appears here. This universe, from the initial energy, would have been producing an expansion and an appearance of matter / antimatter and of the rest of known particles in the terms admitted today, a universe whose expansive dynamic is understood from Einstein's equations, just as they readapted to the description of the expansive universe. This universe is also a universe whose established values show in fact an unmistakable anthropic order. Finally, a universe that, looking to the future, will follow a process of indefinite expansion (without the occurrence of braking, or big crunch) that will end in a thermal death in which the particles will end up absorbed in that baseline or quantum vacuum.

3. THE WAY IN WHICH A HOLISTIC UNIVERSE IT IS PROJECTED ON ITS LAST METAPHYSICAL ONTOLOGY

There is no doubt that the image that science must offer us of the universe, of matter, of life and of man, must make it intelligible that in the evolutionary process there has been the emergence of sensitivity and consciousness. Making intelligible means that science must know the causes that, within the unity of the evolutionary process, have made possible the emergence of sensitivity. Now, since the origin of the biological world, in which sensitivity appears, is the physical world, it can be thought then that this physical world must have an ontological constitution such as to make possible the emergence of sensitivityconsciousness. The universe, in fact, for billions of years was only physical reality. From it, biological reality must have arisen. Is there an alternative to this scientific assumption? It is clear, that it does not exist. If sensitivityconsciousness arose within the biological, then it is evident that its causes must be supposed to be given in the real nature of the physical world that has produced everything evolutionarily.

\subsection{Making intelligible the phenomenological experience of consciousness from the physical world}

We could not doubt that it is obligation of science to address the explanation of the causes of sensitivity and consciousness in the universe. The question is, then, in a strictly scientific field: what is the physical support, that is, the primordial ontology, or real way of being of matter, that makes possible the emergence of the world of sensitivity-consciousness? Science, in fact, must explain why sensitivity-consciousness has been possible evolutionarily. It could not do it except from the ontology, the properties and the laws of the radiationprimordial-matter that originated in the big bang. Now, explain means knowing 
the causes that make possible the emergence of consciousness, according to the phenomenological properties that it has and are described in human sciences. What are these properties?

Theproblem thathasariseninsciencehasbeentoexplain thephenomenological properties of consciousness from the physical world (since, in the evolutionary process, as we said before, everything has its origin in a purely physical universe). For billions of years there was only a physical universe and the psychic universe must have emerged from it. It was, therefore, to understand the "physical support» (the mode of being of the physical world) that made it possible to explain why sensitivity, consciousness, as well as the phenomenological psychic properties of animals and men have appeared in evolution. Therefore, science should explain the psychic properties, but according to the way we perceive them as a fact. The discussion of this explanatory need of science will lead to the metaphysical problem of consciousness (to the projection of this problem on our metaphysical idea of the universe).

Indeed, an idea of the reductionist physical universe (rather based on a merely mechano-classical image of the world) favored for centuries a mechanical and deterministic image of man, as well as an atheistic metaphysics, since it did not make easily intelligible how the universe could relate to God. On the other hand, the modern holistic and field image of the physical universe (founded not only on classical mechanics but also on the strange properties of the quantum world) will not only make possible a non-reductionist and humanist image of man, but also the image of the physical universe in which the possible existence of God as its ontological foundation becomes much more possible, intelligible and therefore credible.

\subsection{Reductionism and classical / quantum balance in the physical explanation of consciousness}

It is known that science was for centuries only mechanical (we have explained it before). From it was born an idea of physical objects, and of classical (Newtonian) interactions among them, which responded only to the principles of mechanism, determinism, splitting, differentiation and distance in a metric space-time (one thing is here and the another there, at a distance, each one keeping his individuality impenetrable against the others). This ended up leading to what we know as reductionism. That is to the pretension of explaining sensitivity-consciousness starting only from those same mechanical principles in which the image of a world of discontinuous and differentiated objects or entities that exert one over another deterministic mechanical actions predominates. Therefore, reductionism does not mean, in our opinion, wanting to explain the psyche from the physical, since this is correct, but to reduce the physical explanation only to classical mechanics, without noticing that the physical universe is also quantum.

However, against this, the New Physics (that of the last seventy years) has insisted little by little that the deep root, let's say ontological, of the world of 
classical objects is the quantum mechanical world in which we know properties that are not fulfilled in the interactions of objects of the classical world. Let's say now, although we do not explain it, that these ontological properties are quantum coherence, quantum superposition, quantum indeterminacy and action-at-distance (or EPR effects). The differentiation between bosonic and fermionic particles is also essential. The latter would have a wave function (a mode of wave vibration) that would keep them independent (as we say in physics, with a spin and a mass of their own). But this does not happen with the bosonic particles that dissolve their vibrational individuality in a state of quantum coherence, unitary and internally undifferentiated (of all this we spoke previously when we discussed the basic ideas of classical mechanics and quantum mechanics, within our ideas current on the standard model).

Hence the current trend of quantum neurology would be to explain living beings not only from classical physics (reductionism), but as a balanced relation between the classical world (the consistent and stable body) and the quantum world (the quantum phenomena imbricated in the classic that would explain what deterministic reductionism could not explain satisfactorily, namely, the unity of consciousness, its indeterminacy or relative freedom and its holistic/ field-dimension). We should deal also with a broader explanation of the way in which neurology is conceived today, within the framework of the evolutionary process and the image of man in contemporary science ${ }^{3}$.

\subsection{The idea of a holistic universe and the verisimilitude of God's holistic ontology}

Therefore, in addition to certain philosophers who anticipated their time (as Nicholas of Cusa), both ancient physics (as is the ether of Newton and his sensorium divinitatis, discredited years later by the Michelson-Morley experiment and the theory of relativity), as the new physics have always tended to postulate the existence of a unitary fund of physical reality, understood as an omni-encompassing holistic background, a sea of energy source, as the implicit

3 The modern image of reality in science includes an idea about the nature of living beings and man. An essential aspect of this explanation is the evolutionary process until the appearance of life and the causes that have produced in the living the capacity to feel, sense, perceive, consciousness and the constitution of a psychic subject capable of directing the response actions to the environment. In front of the animal world, the emergence of reason has been the main evolutionary factor that explains the appearance of man with his specific psychism, that is, with the emotional-rational aspects of his behavior. Man, like animals, is explained today in science in a monist perspective: it is only the constituent matter of the universe that, through evolution, has produced man and is the one that explains its nature. Man is thus a balance between a body built in the classical world (this explains its stability, its identity, its individuality, necessary to build its own history) and a body that shows phenomena in which matter is presented in its quantum properties (these properties are what explain the properties of the human psyche). Man is thus a classical/quantum balance, a balance between determination and indeterminacy. 
universe of Bohm, as the recent quantum vacuum, as the reference fund for the operators of creation and destruction of Dirac (which he formulated already in the first years of the birth of quantum mechanics), or how the referential fund in which he is born or in which he finally dissolves the energy of the universe. Recall that the standard cosmological model requires an ontological reference background that gives birth to the energy of the universe and in which it will finally dissolve.

This unitary profound field of the universe is what seems to have been confirmed by the existence of the Higgs field, which permeates the universe as a whole, and its vibration in the form of a Higgs boson that would confer mass to the vibrations generated from the big bang. In this way, the particles, or fermionic vibrations, would acquire the mass that gives birth to the objective mechanical world. Ordered macroscopic objects, physical and biological, which among other things form the universe and allow us to have a stable body with which to build a personal biography. The theory and experimental verification of the Higgs field/boson - according to its role in the standard model of particle theory - contributes in our days in a new way, for the first time experimentally endorsed, to consider the existence of a unitary fund that universally permeates space. Thus, the standard model, reaffirmed by Higgs, assumes with new strength the unitary vision of matter that constitutes the universe; unitary matter that manifests as bosonic and as fermionic particles, but always within a deep ontological unit that permeates the bottom of the universe.

By contributing, therefore, from its own conceptual perspective, to founding a holistic image of the universe, the Higgs field/boson approaches science in a meaningful way to the likelihood of attempts to explain the nature of sensitivityconsciousness from the pitched quantum properties of matter and the physical universe. Note that the Higgs field/boson theory is only purely physical, does not by itself imply an explanation of the psyche, nor does it make any reference to God. But it is a scientific result that facilitates the conceptual effort of scientists and psychologists (as it is in the human sciences), effectively engaged in the explanation of living beings as a balanced classical/quantum equilibrium. Higgs tells us that physical reality is constituted by previous primordial fields that found the appearance of the classical world, but that are not yet caught in the deterministic and differentiated rigidity of that classical world. Higgs, even without knowing it, has opened a door to the explanation of the surprising fact that evolution has generated sensitivity and consciousness.

\subsection{The physical image of the universe and the viability of the image of God}

The viability of the hypothesis of a universe created by the work of a transcendent metaphysical being understood as God, as the theistic metaphysics does, depends in large part on the ontology of the physical world, as it is known by science. The idea of God would suppose a holistic presence that embraces the whole universe as its deepest background. This is the experience of religious 
man who always finds God in the depths of his being. In addition, that divine source field ontology would be what would have given birth to the universe as creation. The experience of a God that embraces the deep ontology of the entire universe is essential not only for the religious experience, but also to explain how God can be the profound origin of all things, the radical ontology from which the universe is born.

Well, the truth is that the reductionist image of science, still remaining in some, is limited only to a mechanical-deterministic image. This image did not favor, for many years, the viability of the idea of God. The universe appeared for classical reductionism as a plurality of disintegrated entities, separated from each other, which made it difficult to understand the deep holistic unity of the universe. But reductionism not only did not favor imagining the holistic presence of God in the universe, but it made unfeasible even the same humanism that we all see in our social experience. It made the indeterministic and holistic explanation of living beings unviable. Reductionism would lead to a robotic idea of living beings, as we see today in modern computational psychologies, which are the modern version of the nineteenth-century deterministic mechanism. This mechanistic robotism could never explain the phenomenological properties of the animal and human psyche (the unity of consciousness, the field experience and the indeterminacy of responses to the environment). The classic reductionist mechanicism, mechanistic and deterministic, could never come to explain the indeterminism and field holism, as they are given phenomenologically in the animal and human experience.

Hence, the New Physics, by making us see the importance of the universe not only being mechanical but at the same time, in its primitive ontological root, also quantum mechanical, has contributed to make more and more credible the idea of God as a profound field reality of the universe. To understand that the universe is not a mosaic of splintered, isolated, purely classical entities, but a unitary entity that responds to the holistic fields ontology in which the universe exists, has been a change of scientific perspective that certainly makes it more plausible than after that the background as physical field that science peeks to postulate as a physical concept - and also today to test experimentally and to describe with only scientific concepts - could in some way hide the enigma of the holistic presence of the ontology of divinity (in a way that we do not know). In it the universe would have been produced and in it would be sustained in the being continually by the divine will (I insist that these considerations are only theistic philosophy, legitimate as philosophy, but they are not acceptable in science as pure science as such).

In other words, insofar as science comes close to understanding the universe as a holistic unit, science makes divine holism all the more plausible. The connection of this physical holism with the profound field idea of God, however, would not be science as such, but a legitimate philosophical interpretation of theism. 


\subsection{A holistic universe of psychic ontology continues to make atheism viable}

Well, in this sense, the discovery of the Higgs field/boson should be understood as the first great experimental verification that the universe exists effectively immersed in a holistic field that is described as the Higgs field (although this, as we said before, it should not be confused with the pitched background of the universe, prior to the big bang, from which it is born and in which the total energy of the universe is reabsorbed). Until now there was a lot of speculation about the pitched background of reality. From now on, at least the Higgs field is already part of experimental science. We know that we are in a universe that responds to a holistic ontology. And in this sense, it is more likely to think today about the divine profound source of ontology of the universe that, if it existed, should also be holistic and be beyond the Higgs field. In this sense we believe that the discovery of the Higgs field/boson contributes to make the philosophical speculation of theism more plausible. Philosophical similarity, we insist, which, of course, does not eliminate the possibility of the alternative interpretation, also philosophical, of the universe in an atheistic hypothesis.

But we must do an observation. To admit that the primal psychic quality of the ontology of matter must be postulated does not imply necessarily a theistic metaphysics ${ }^{4}$. Why then does matter have the property of producing sensitivityconsciousness, as evolution shows and we must postulate? Why do not matter have it? We will never know, but in our universe, we must attribute that property to matter because without it, the later factual products of evolution could not be explained. We must also observe that the primordial matter could have a psychic ontology and, nevertheless, be a natural system that is self-sufficient, purely mundane, without God. Therefore, we must explicitly say that admitting the psychic ontology of matter is not a crucial assumption that allows one to decide between theism and atheism.

However, even though all this is so, there is also no doubt that, behind the Higgs boson field, the door to a greater likelihood of the hypothesis of God as the profound source foundation of the universe opens for the theist metaphysics. This door was not open at a time when only reductionism predominated. If we live in a universe that floats in a pitched and holistic reality to which a deep psychic ontology can be attributed, then that universe makes us much more likely to think that it could be produced by a divine ontology in the background whose transparency or absolute consciousness could be glimpsed in the psychic fields of sensitivity-consciousness that have been opening up in

$4 \quad$ Recall that, as we inferred earlier, explaining that in the evolution of the physical universe has occurred the emergence of sensitivity-consciousness, implies that the ontological properties of the primordial matter should be such that, at a certain moment of the evolution, there is the emergence of sensation, sensitivity, perception and consciousness. That is, that the psychic world emerges. Well, what we now explain is that postulating that matter is the primordial germ of the psychic world is also compatible with an atheistic explanation of the universe. That said, while admitting that the deep «psychic» nature of the physical world also makes the hypothesis of a Divinity that should be holistic more plausible. 
the evolutionary process (and, in this sense, I point out that the Tzim-Tzum theory in Jewish Kabbalah is still suggestive).

A science that described the physical world in a blind way, without sensitivityconscience, a robotic image, mechanicism and determinism, would not be humanistic nor would it be appropriate to understand the religious world. But that science, in fact, would not be science because its obligation is to explain that in evolution the unquestionable fact of sensitivity-consciousness has occurred. And what this explanation demands leads science to a holistic image of the universe that, even making the holistic ontology of God more believable, nevertheless, does not thereby close the door to an atheistic explanation, without God, of the universe. Therefore, the problem of the origin and nature of sensitivity-consciousness leaves us still mired in metaphysical uncertainty. Science does not allow us to get out of doubt about the ultimate metaphysical truth of the universe.

\subsection{The image of the universe in the Tzim-Tzum}

The Kabbalistic movement is a school of Jewish thought that takes hold in the 11th-12th centuries, whose roots can be found in very ancient times, in the last centuries before Christ and in the first centuries of the Christian era. The kabala are philosophical ideas (they are not science, they are imagination or religious-philosophical speculation) that lead by themselves to a spirituality oriented towards mysticism. Many of the images of Kabbalah —above all its description of the creation of the evolutionary universo - are of extraordinary beauty, are congruent with many of the current results of science and can be considered a patrimony of universal religiosity.

\section{The kabalistic movement}

The kabbalistic movement has many facets, historical periods and authors that must be studied specifically. Kabbalah has been a philosophical, spiritual and mystical movement, but also a group of initiatory, esoteric believers, cultivators of a mystery, symbolic theosophy of access keys to knowledge through a certain linguistic cryptography connected with the interpretation of the Bible. Since all this is historical truth, it is also true that there are reasons that explain why kabbalah was inclined to organize in esoteric-mysterious circles.

In our opinion, what catches the attention of the non-Jewish observer (for example, Christian) in the thought of the kabala is his vision of God, of the universe and of the creative process, of life and of the human being, and at the same time, of the spirituality that this way of understanding reality leads to. The interest is not in the esotericisms, in the linguistic cryptography of the Sacred Scriptures or in certain quasi-magical or superstitious rituals that could have adhered to historical times very different from ours (magical rituals and superstitions that, on the other hand, are also present in all religions, and certainly in Christianity and Islam). 
The «return» to the origin, to the divine unity (the Light), will take place at the end of time, but through mystical spirituality the «return» may already be taking place in the life of the believer. Hence, kabala is not only a way of understanding the harmony of everything in God, but, at the same time, a way or path to realize through mystique the union with nature and with God. The unity of the universe in God inspires the experience of the believer's mystical path.

\section{The school of Gerona: Isaac the Blind}

The great question was, for the school of Gerona, how to understand that the primordial divine unity produces a universe that, being different from God, nevertheless forms an ontological unit with the same divinity. The kabala of Gerona was aware that her vision was an expression of faith: it was a way of understanding that made the Jewish faith in a creator God credible and understandable. The fundamental reasons were: the idea of transcendent God, the idea of the world, the idea of God-world unity, and the idea of the final return of everything to God through the mystique of a union with the world that leads to divinity.

The insistence on the idea of God as «Nothing» was a way of accentuating the transcendent character of God: this is not «nothing of the world», it is not something proper to the world, its essence does not respond to anything finite. God did not create the world (as was thought in Neoplatonism) by using something like, say, a "pre-existing matter.» God set in motion the creative process from itself and from nothing; that is, «ex nihilo» (obviously, according to the later Latin expression in Christianity, only assuming the divine entity itself). The kabala of Gerona insists that God produces the universe from himself: that is why God embraces all reality and is immanent to it. But, on the other hand, the kabala also insists on the transcendence of God: it creates the universe by a free decision (without Neoplatonic determinisms) and always remains transcendent reality. God does not identify with the world or is a part of it. But the world is born of God, is created «in God». The great question of substance is therefore: how to understand that immanence and, at the same time, transcendence of God in relation to the world?

Also of the south of Europe, related to Isaac the Blind and the School of Gerona, is the treaty titled Sefer ha-Iyyum or «Book of the Speculation», of anonymous authors and of obscure origins. It has a special interest because the themes of the Sefirot, the Zohar, and, above all, because there is a use of the symbolism of light to explain the way in which the creation of the world from the Divinity occurs. This symbolism of light, as we shall see, is the great contribution of lurian kabbalah in the sixteenth century.

\section{Luria: God, the Light and the Tzim-Tzum}

Isaac ben Solomon Luria, born in Jerusalem in 1534 and died in Safed in 1572. Luria has left no author works identified, but his teaching was picked up 
by Vital Hayyim (1543-1620) who wrote Etz Hayyim or «Tree of Life», which happens to be the canonical work for the knowledge of lurian kabbalah. Luria's work represents a considerable effort of the Kabbalistic tradition to imagine how the emergence of the universe in God could take place, according to the principles of immanence and divine transcendence.

The believer, however, while being aware of that final enigma, has always tried to «imagine» how the birth of the universe in God might be possible. Jewish theological orthodoxy also imposed (also in other religions, such as Christianity) that the creative act of God was understood «ex nihilo» (creation of nothing, even assuming only the existing reality of God), that it was also a free creation, and that God remained both immanent and transcendent to the created universe. The thought of Luria in his commentary on the Zohar represents a beautiful effort of imagination based on the image of light.

1) Light, the primordial nature of God. For kabbalah, God is understood as the «nothingness» of the finite world. But for Luria a phenomenon of the finite world, light, is taken as an image of the divine nature. The primordial light fills (in an unknowable way for us) the totality of the divine essence and is the principle of the Sefirot. Only God is real and existent, being totally full of light. This image of light has been used by many religions and mystical experiences. Let us remember Saint John who in his First Letter says: "God is light and in Him there is no darkness at all».

2) The Tzim-Tzum as a form of creation. If creation is ex nihilo and only the existing reality of God is presupposed, full of light, the problem of how to conceive the creative process is presented to the believer. Where does creation occur? Is the world «outside of God»? Let us think that Jewish theological orthodoxy (as well as Christian orthodoxy) demanded to think of God as immanent and transcendent to the created universe. Luria offers a suggestive image that leads us to intuit what creation could be: God could produce in himself something like a "contraction», a «void», a Tzim-Tzum or «retraction» of the divine light in which he would reign the absolute darkness. This emptiness would be encompassed by the presence of the Divine, but in some way the light would have withdrawn from it. But in the realm of the divine a «space» for the non-divine would have appeared. Let's think that if we do not know what the divine essence is -talking about light as its essence is already an image - we can hardly understand conceptually what a "contraction» of the luminous essence of God could mean. That is why the strength of the image proposed by Luria (contraction, emptiness, divine Tzim-Tzum) is its capacity for suggestion by analogical way (metaphor, similarity). If speaking of "person» is an analogy of the divine essence, speaking of «Tzim-Tzum» would also be an analogy of the creative process.

3) Creation as light in darkness. The creation would have continued for Luria when from the Infinite Light a beam of light is introduced into the «empty and dark space». Later this light would have been divided, being enclosed in conduits, vessels or finite filaments that, when breaking in part, produce matter and, ultimately, the fracture of the primordial unit of light. This matter, in the sense of «shells» or shells that «enclose» light and break the unitary harmony of light, is the origin of the world, its finitude and cause of evil in non-divine reality. The created world is thus 
a fracture of the harmony of light that creates differentiation and tension between some things and others: this is the origin of evil, of the lack of harmony that must be recovered in the course of history.

4) Natural history as a restoration of universal harmony. History is for Luria the occasion to restore the primitive harmony, or unity of the light in the divine identity. In evolution, living beings are organizations that restore to a certain degree the unity between the disintegrated and the return to the unitary realms of light. The universal evolution is a process of return to the divine that «saves» the particles of disintegrated light producing the "restoration». It is evident that for Luria man is the essential protagonist in the process of restoration planned in God's plan and carried out by the divine faculties described in the Sefirot.

5) The mystical itinerary of Israel. The work of man, the work of restoration of universal harmony - the return to the light of God - is directed by the people who have been chosen, by Israel. Luria thus links with the Jewish orthodoxy to consider that it is the fulfillment of the law and the ritual prescriptions where Israel remains faithful to the divine election. But, in addition, the mystical way is the true way in which the human soul ascends to higher levels more harmonious with a nature and a society less and less fractionated, until coming into contact with the absolute final unity of the Light of Divinity. Luria's pietism (later valued in modern Jewish Hasidism or Pietism) leads, therefore, to asceticism, contemplation and mystical experiences as a form of «unification» (yihud) with the divine life, as a progressive insertion in the Light.

In addition to these fundamental ideas, Luria also provides other explanations, most of which already belong to the previous forms of Kabbalistic thought. It assumes the Kabbalistic idea of the "reincarnation» of the soul and relates it to the process of «salvation», «restoration» or "progressive unification» that happens in history. It also explains the way in which Kabbalistic ideas-those discussed here and others more detailed-are encrypted in letters and numbers, hidden in the Holy Scriptures. For the «external observer» it is more difficult to see the value of these and many other aspects of kabbalah. However, this does not subtract an apex from the beauty of the "conceptual allegory of light» with which Luria conceives what the immanent and transcendent creation of the universe could be in the unitary background of the divine ontology.

\section{Kabbalah and science}

The beautiful allegory of Luria has an extraordinary force of suggestion because it makes "allegorically» credible that from the unitary divine identity a universe of differences was produced that is led back to the primordial unity. The beautiful metaphor continued - this is allegory - of the divine essence as Light is the image of a process that has not a few points of contact with the conceptual image of the universe, of life and of man in modern science.

Suffice it to say, however, that modern cosmology contemplates the genesis of the universe in the primordial radiation produced in the Big Bang. When 
the energy cools, the birth of the particles occurs as an «encapsulation» that gives rise to differentiation. The appearance of fermionic matter as a structure of differentiated particles produces the world of individual objects in spacetime. However, in living beings systems of interaction with fields of reality or fields of bosonic matter are opened, where the unity of the universe is felt and the final unity is pointed out. The advance of holistic thinking in physics and its connection with current hypotheses to explain biological consciousness and evolution, certainly opens perspectives in which the advanced allegorical images of Luria in the sixteenth century resonate with a special force. In any case, the conceptual allegory of Luria built from the image of the Light, even without being «science», makes «believable» the belief in a God who from himself, ex nihilo, sets in motion the amazing process of creation of a universe that «is not God,» but that «is in God.»

As the Kabbalists themselves say, these ideas contribute to the universal heritage of religions. We believe that it is. Knowing them -in their historical dimension and in the current scientific discussion - is today an important element of culture for reflection on the great humanistic, metaphysical, scientific and religious issues.

REFERENCIAS (Dada su extensión presentamos esta bibliografía en forma comprimida)

ABBOTT, L., SEJNOWSKI, T. J. (Eds.) (1999), Neural Codes and Distributed Representations. Foundations of Neural Computation, Bradford Book, CambridgeMassachussets, London, England, MIT Press. ACZEL. A. D. (2001), Entanglement, New York, Plume Book. ANDERSEN, P. B., et al. (2000), Downward Causation: Minds, Bodies and Matter, Aarnus, Dinamarca, Aarnus University Press. ANDERSON, JAMES A., ROSENFELD EDWARD (Eds.) (1998), Talking Nets. An Oral History of Neural Networks, Bradford Book, Cambridge-Massachussets, London, England, MIT Press. BALLESTEROS, SOLEDAD (2002), Psicología General II: Atención y Percepción, Madrid, UNED. BEAR, M.F., CONNORS, B. W., PARADISO, M. A. (1998), Neurociencia. Explorando el Cerebro, Barcelona, Masson - Williams \& Wilkins.

BEAUREGARD, M. (Ed.) (2003), Consciousness, Emotional Self-Regulation and the Brain, Amsterdam, Benjamin. BECK, F., ECCLES, J. (2003), «Quantum Processes in the Brain: A scientific basis of Consciousness», en: OSAKA, N. (Ed.), Neural Basis of consciousness, Amsterdam: Benjamins, 141-166. BEORLEGUI, CARLOS, «Los emergentismos sistémicos: Un modelo fructífero para el problema mente-cuerpo», en: Pensamiento, vol. 62 (2006) 391-439. BOHM, D. (1952), «A Suggested Interpretation of Quantum Theory in Terms of Hidden Variables», en: Physical Review, 85, 166-179. BOHM, D. (1980), La totalidad y el orden implicado, Barcelona, Kairós. BOHM, D. (1986), "A New Theory of the Relationship of Mind to Matter», en: Journal of the American Society for Physical Research, 80, 113-135. BOHM, D. (1990), "A new Theory of the relationship of Mind to Matter», en: Philosophical Psychology, 3, 271-286. BOHM, D., HILEY, D.J. (1993), The Undivided Universe, London, Routledge. BOHR, N. (1958), Atomic Physics and Human Knowledge, New York, Routledge. BRUCE GOLDSTEIN, E. (2006), Sensación y percepción, $6^{\text {a }}$ Edición, Madrid, Thompson-Paraninfo. BUCKLEY, P., PEAT, D. (Eds.) (1996), Glimpsing Reality. Ideas in Physics and the Link to Biology, 
Toronto, University of Toronto Press. CABEZA, R., KINGSTONE, A. (Eds.) (2001), Handbook of Functional Neuroimaging of Cognition, Cambridge-Massachussets, London, England, MIT Press. CARTER, RITA (1998), El nuevo mapa del cerebro, Barcelona, RBA Ediciones. CASTRO GARCIA, ÓSCAR, «Aspectos biosemióticos de la conciencia. En búsqueda de los signos de la vida y su referencia a la conciencia como principio teleonómico», en Pensamiento, vol. 62 (2006) 471-504. CHALUPA, L. M., WERNER, J. S. (Eds.) (2004), The Visual Neurosciences, Bradford Book, Cambridge-Massachussets, London, England, 2 vol. CRESPO, ANTONIO (2007), Cognición Humana. Mente, Ordenadores y Neuronas, 2da. Edición, Madrid, Editorial Centro de Estudios Ramón Areces. COBOS CANO, P. L. (2005), Conexionismo y cognición, Madrid, Ediciones Pirámide. DAMASIO, Antonio (1994), Descartes' Error: Emotion, Reason, and the Human Brain, New York, Quill/HarperCollins Publishers Inc. DAMASIO, Antonio (1999), The Feeling of What Happens: Body and Emotion in the Making of Consciousness, Florida, Harcourt, Inc. DAMASIO, Antonio (2003), Looking for Spinoza: Joy, Sorrow, and the Feeling Brain, Florida, Harcourt, Inc. DAVYDOV, A. S. (1982), Biology and Quantum Mechanics, Oxford, Pergamon Press. ECCLES, J. (1990), "A Unitary Hypothesis of Mind-Brain Interaccion in the Cerebral Cortex», en: Proceedings of the Royal Society of London, 240, 433-451. ECCLES, J. (1994), How the Self Controls its Brain, Berlin, Springer. EDELMAN, G. M., Mountcastle, V. B. (1978), The Mindful Brain: Cortical Organization and the Group-Selective Theory of Higher Brain Function, MIT Press, Cambridge, Mass. EDELMAN, G. M. (1987), Neural Darwinism: The Theory of Neuronal Group Selection, Basic Books, Nueva York. EDELMAN, G. M. (1988), Topobiology: An Introduction to Molecular Embriology, Basic Books, Nueva York. EDELMAN, G. M., Tononi, G. (2000), A Universe of Consciousness: How Matter Becames Imagination, Basic Books, Nueva York. EDELMAN, G. M. (2001), Building a Picture of the Brain, In: Edelman, G. M., Jean-Pierre Changeux (Ed.), The Brain, Transaction Publishers, New Brunswick - London. EDELMAN, G. M. (2004), Wider than the Sky: the Phenomenal Gift of Consciousness, Yale University Press, New Haven - London. EDELMAN, G. M. (2006), Second Nature: Brain Science and Human Knowledge, New Haven - London, Yale University Press. EDELMAN, G., CHANGEUX, J. P. (Eds.) (2001), The Brain, New Brunswick (USA), London (U.K.), Transaction Publishers. EINSTEIN, A., PODOLSKY, B., ROSEN, N. (1935), «Can Quantum-Mechanical Description of Physical Reality Be Considered Complete», en: Physical Review, 47, 777ss. FODOR, JERRY (1998), In Critical Condition. Polemical Essays on Cognitive Science and the Philosophy of Mind, Bradford Book, Cambridge-Massachussets, London, England, MIT Press. FODOR, JERRY (2000), The Mind Doesn't Work That Way. The Scope and Limits of Computacional Psychology, Bradford Book, Cambridge-Massachussets, London, England, MIT Press. FRÖHLICH, H. (1968), «Long Range Coherence and Energy Storage in Biological Systems», en: International Journal of Quantum Chemistry, 2, 641 649. FRÖHLICH, H. (Ed.) (1988), Biological Coherence and Response to External Stimuli, Berlin, Springer Verlag. FUSTER, JOAQUÍN M. (2003), Cortex and Mind. Unifying Cognition, Oxford, Oxford University Press. GEGENFURTNER, K. R., SHARPE, L. T. (eds.) (1999), Color Vision. From Genes To Perception, Cambridge, Cambridge University Press. GISOLFI, CARL V., MORA, FRANCISCO, The Hot Brain. Survival, Temperature, and the Human Body, Cambridge-Massachussets, London, England, Bradford Book, MIT Press. GOLDSTEIN, BRUCE E. (Ed.) (2005), Blackwell Handbook of Sensation \& Perception, Malden Massachussets, Blackwell Publishing. GRAY, WAYNE D. (Ed.) (2007), Integrated Models of Cognitive Systems, Oxford, Oxford University Press. HAGEN, S., HAMEROFF, S., TUSZYNSKI, J. (2002), "Quantum Computation in Brain 
Microtubules: Decoherence and Biological Feasibility», en: Physical Review, E65, 061901-1 - 061901-11. HAYNES, DUANE E. (2004), Principios de Neurociencia, 2da. Edición, Barcelona, Elsevier Science. HAMEROFF, Stuart, Penrose, Roger (1996), «Orchestrated Reduction of Quantum Coherence In Brain Microtubules: A Model for Consciousness", In: Toward a Sciences of Consciousness, The First Tucson Discussions and Debates, eds. Hameroff, S. R., Kaszniak, A. W. and Scott, A. C., Cambridge, MA: MIT Press, pp. 507-540. HAMEROFF, S., PENROSE, R. (1996), "Orquestrated Reduction of Quantum Coherence in Brain Microtubules: A model for Consciousness», en: Journal of Consciousness Studies, 3, 36-53. HAMEROFF, Stuart (1996), "Conscious Events As Orchestrated Space-Time Selections», In: Journal of Consciousness Studies, 3 (1): 36-53. HAMEROFF, Stuart (1998), "Quantum Computation In Brain Microtubules? The Penrose-Hameroff «Orch OR» Model of Consciousness», In: Philosophical Transactions Royal Society London (A) 356:1869-1896. HAMEROFF, Stuart (1998), «Did Consciousness Cause the Cambrian Evolutionary Explosion?», In: Hameroff, S. R., Kaszniak, S. R., Scott, A. C. (eds.), Toward a Science of Consciousness II: The Second Tucson Discussions and Debates, Cambridge, MA: MIT Press, pp. 421-437. HAMEROFF, Stuart (2003), «Time, Consciousness and Quantum Events in Fundamental Spacetime Geometry», In: Bucceriu, R., Saniga, M., Proceedings of a NATO Advanced Research Workshop. HAMEROFF, S. (2003), Ultimate Computing. Biomolecular Consciousness and Nanotecnology, Tucson, Arizona, Personal Edition. HAMEROFF, Stuart (2004), "Quantum States in Proteins and Protein Assemblies: The Essence of Life?», In: Proceedings of SPIE Conference on Fluctuation and Noise, Canary Islands, June 2004. HAMEROFF, Stuart (2004), "Quantum States in Proteins and Protein Assemblies: The Essence of Life?», In: Proceedings of SPIE Conference on Fluctuation and Noise, Canary Islands, June 2004. HAMEROFF, Stuart (2006), "Consciousness, Neurobiology and Quantum Mechanics: The Case for a Connection», In: Tuszynski, Jack (ed.), The Emerging Physics of Consciousness, Berlin-Heidelberg, Springer-Verlag. HAMEROFF, Stuart (2004), "Quantum States in Proteins and Protein Assemblies: The Essence of Life?», In: Proceedings of SPIE Conference on Fluctuation and Noise, Canary Islands, June 2004. HARRIS, L., JENKIN, M. (Eds.) (2007), Computational Vision in Neural and Machine Systems, Cambridge, Cambridge University Press. HEYES, CECILIA, HUBER, LUDWIG (Eds.) (2000), The Evolution of Cognition, Bradford Book, CambridgeMassachussets, London, England, MIT Press. HINTON, GEOFFREY, SEJNOWSKI, TERRENCE J. (Eds.) (1999), Unsupervised Learning. Foundations of Neural Computation, Cambridge-Massachussets, London, England, Bradford Book, MIT Press. JIBU, M., YASUE, K. (1995), Quantum Brain Dynamics and Consciousness, Amsterdam, Benjamins. KANDEL, E. R., SCHWARZ, J. S., JESSELL, T. M. (2000), Principles of Neural Science, $4^{\text {th }}$ edn, New York, McGraw-Hill. KANDEL-SCHWARZ-JESSELL (2003), Neurociencia y Conducta, Madrid, Prentice-Hall. KANDEL, E. R. (2006), In Search of Memory. The Emerging of a New Science of Mind, New York, Norton \& Company. KAUFFMAN, S. (1993), The Origins of Order: Self-Organization and Selection in Evolution, Oxford, Oxford University Press. KAUFFMAN, S. (1995), At Home in the Universe: The Search for the Laws of Self-Organization and Complexity, New York, Oxford University Press. KOCH, CHRISTOFF (2004), The Quest for Conscoousness. A neurobiological Approach, Englewood, Colorado, Roberts and Company Publishers. LAUGHLIN, R. B. (2005), A Different Universe. Reinventing Physics from the Bottom Down, New York, Basic Books. LIBET, B. (1985), "Unconscious Cerebral Initiative and the Role of Conscious Will in Voluntary Action», en: Behavioral and Brain Sciences, 8, 529-566. LIBET, B. (2003), «Cerebral Physiology of Conscious Experience: Experimental 
Studies», en: OSAKA, N., Neural Basis of Consciousness, Amsterdam, Benjamins. LIBET, b. (2004), Mind Time: The temporal Factor in Consciousness, Cambridge Massachussets, Harvard University Press. LUNA, DOLORES, TUDELA, PÍO (2006), La percepción visual, Madrid, Trotta. LLINÁS, R., CHURCHLAND, P.S. (1996), The Mind-Brain Continuum, Cambridge Massachussets, MIT Press. McCRONE, J. (1999), Going Inside: A Tour Round a Single Moment of Consciousness, London, Faber and Faber. McFADDEN, J. (2000), Quantum Evolution: The New Science of Life, New York, W.H. Norton. MARGULIS, L., SAGAN, D. (1995), What is Life? New York, Simon and Schuster. MONSERRAT, J. (1996), "Francis Crick y la emergencia de la conciencia visual», In: Pensamiento, vol. 52 (1996) 241-252. MONSERRAT, J. (2000), "Penrose y el enigma cuántico de la conciencia», In: Pensamiento, vol. 56 (2000) 177-208. MONSERRAT, J. (2001), «Engramas neuronales y teoría de la mente», In: Pensamiento, vol. 57 (2001) 176-211. MONSERRAT, J. (2002), «John Searle en la discusión sobre la conciencia», In: Pensamiento, vol. 58 (2002) 143-159. MONSERRAT, J. (2003), «Teoría de la mente en Antonio R. Damasio», In: Pensamiento, vol. 59 (2003) 177-213. MONSERRAT, J. (2005), "Génesis evolutiva de la representación y del conocimiento», en: Martínez-Freire, Pascual F., Cognición y representación, Contrastes, Suplemento 10, Málaga 2005, 51-70. MONSERRAT, J. (2006), «Gerald M. Edelman y su antropología neurológica: Presentación y discusión de su teoría de la mente», In: Pensamiento, vol. 62 (2006) 441 170. MONSERRAT, J. (2007), «Neural Networks and Quantum Neurology: Speculative Heuristic Towards the Arquitecture of Psychism», en: Mira, J., Álvarez, J. R. (Eds.), Bioinspired Modeling of Cognitive Tasks, Berlin-Heidelberg, Springer Verlag. Part I, 1-20. MORA. F. (Ed.) (1995), El problema cerebro-mente, Madrid, Alianza Editorial. MORA, F. (Ed.) (2000), El cerebro sintiente, Barcelona, Ariel. MORA, F. (Ed.) (2004), Esplendores y miserias del cerebro, Madrid, Fundación Santander Central Hispano. MORA, F. (2007), Neurocultura, Madrid, Alianza Editorial. MUNAR, E-, ROSSELLÓ, J., SÁNCHEZCABACO, A. (Eds.) (1999), Atención y percepción, Madrid, Alianza Editorial. MURPHY, NANCEY, BROWN, WARREN S. (2007), Did My Neurons Make Me Do It? Philosophical and Neurobiological Perspectives on Moral Responsibility and Free Will, Oxford, Oxford University Press. NADEAU, R., KAFATOS, M. (1999), The Non-local Universe: The New Physics and Matters of the Mind, New York, Oxford University Press. NIELSON, M., CHUANG, I. L. (2001), Quantum Computation and Quantum Information, Cambridge, Cambridge University Press. NICHOL, L. (Ed.) (2003), The Essential David Bohm, London, Routledge. O’REILLY, RANDALL C., MUNAKATA, Y., (2000), Computational Explorations in Cognitive Neuroscience. Understanding the Mind by Simulating the Brain, Cambridge-Massachussets, London-England, Bradford Book. MIT Press. OSHERSON, DANIEL N. (Ed.) (1998), Methods, Models, and Conceptual Issues, Cambridge-Massachussets, London, England, MIT Press. PALMER, S. E. (1999), Vision Science. Photons to Phenomenology, Bradford Book, Cambridge-Massachussets, London, England, MIT Press. PARASUNAMAN, RAJA (Ed.) (1998), The Attentive Brain, Bradford Book, Cambridge-Massachussets, London, England, MIT Press. PASHLER, H. (1998), The Psychology of Attention, Cambridge, Massachussets, MIT Press. PARKS, R. W., LEVINE, D. S., LONG, D. L. (Eds.) (1998), Fundamentals of Neural Network Modeling. Neuropsychology and Cognitive Neuroscience, Bradford Book, Cambridge-Massachussets, London, England, MIT Press. PEAT, F. D. (1997), Infinite Potential. The Life and Times of David Bohm, New York, Perseus Publishing. PENROSE, Roger (1989), The Emperor's New Mind, Oxford, Oxford University Press. PENROSE, Roger (1994), Shadows of the Mind: A Search for the Missing Science of Consciousness, Oxford, Oxford University Press. PENROSE, Roger (1997), The Large, the Small and the Human Mind, Cambridge, 
Cambridge University Press. PENROSE, Roger (2005), The road to reality: a complete guide to the laws of the universe, New York, Knopf. PRIBRAM, KARL H. (1991), Brain and Perception. Holonomy and Structure in Figural Processsing, Hillsdale, New Jersey, L. Erlbaum Publishers. PURVES, DALE, Y OTROS (Eds.) (2006), Neurociencia, $3^{\mathrm{a}}$. Edición, Buenos Aires, Editorial Médica Panamericana. RAMACHANDRAN, V.S., BLAKESLEE, S. (1998), Phantoms in the Brain, New York, William Morrow. RAMACHANDRAN, V.S., HUBBARD, E.M. (2001), "Psychophysical Invetigations into the Neural Basis of Synaesthesia», en: Proceedings of the Royal Society of London, B 268: 979-983. RAMACHANDRAN, V.S. (2003), "Hearing Colors and Testing Shapes», en: Scientific American, May: 52-59. RAMACHANDRAN, V.S. (2004), A Brief Tour of Human Consciousness, New York, Pi Press. SANCHEZ RON, J. M. (2005), Historia de la Física Cuántica: I. El período fundacional (1860-1926), Barcelona, Crítica. SCHRÖDINGER, E. (1999), Mente y Materia, Barcelona, Tusquets. SCOTT, A. C. (1995), Stairway to the Mind, New York, Springer Verlag. SCOTT, A. C. (2002), Neuroscience: A Mathematical Primer, New York, Springer-Verlag. SCOTT, A. C. (2003), Non-linnear Science: Emergence and Dynamics of Coherent Structures, 2nd. Edn, Oxford, Oxford University Press. SHEPHERD, G. M. (2001), The Synaptic Organization of the Brain, 4 edn, New York, Oxford, Oxford University Press. SQUIRE, L., KOSSLYN, S. M. (Eds.) (1998), Findings and Current Opinion in Cognitive Neuroscience, Cambridge-Massachussets, MIT Press. SPENDE, CHARLES, DRIVER, JON (Eds.) (2004), Crossmodal Space and Crossmodal Attention, Oxford, Oxford University Press. STAPP, H. (1999), "Attention, Intention and Will in Quantum Physics», en: Journal of Consciousness Studies, 6, 143-164. STAPP, H. (2001), "Quantum Theory and the Role of Mind in Nature», en: Fountations of Physics, 31, 1465-1499. STAPP. H. (1993-2004), Mind, Matter, and Quantum Mechanics, Heidelberg-Berlin, Springer. STERNBERG, ROBERT J. (Ed.) (1999), The Nature of Cognition, Cambridge-Massachussets, London, England, MIT Press. TEGMARK, M. (2000), «Importance of Quantum Decoherence in Brain Processes», en Physical Review, E61, 4194-4206. THAGARD, PAUL (2000), Mind. Introduction to Cognitive Science, Bradford Book, Cambridge.Massachussets, London, England, MIT Press. TUCKER, DON M. (2007), Mind from Body. Experience from Neural Structure, Oxford University Press. TUSZYNSKI, Jack A., Woolf, Nancy (2006), «The Path Ahead», In: Tuszynski, J.A. (Ed.), The Emerging Physics of Consciousness, Berlin-Heidelberg, Springer-Verlag, pp. 1-25. TUSZYNSKI, Jack A. (Ed.) (2006), The Emerging Physics of Consciousness, BerlinHeidelberg, Springer-Verlag. VARELA, FRANCISCO J. (1990), Conocer. Las ciencias cognitivas: tendencias y perspectivas. Cartografía de las ideas actuales, Barcelona, Gedisa. VELMANS, M. (2000), Understanding Consciousness, London, Routledge. Von NEUMANN, J. (1953-1955), Mathematical Foundations of Quantum Mechanics, Princeton, Princeton University Press. Von NEUMANN, J. (1958), El ordenador y el cerebro, Barcelona, Bon Ton. WOLFF, Nancy, HAMEROFF, Stuart, "A Quantum Approach to Visual Consciousness», In: Trends in Cognitive Science, vol 5, n 11, November 2001, pp. 472-478. WOLFE, JEREMY M., Y OTROS (2006), Sensation \& Perception, Sunderland, Massachussets, Sinauer Associates Publishers. ZELAZO, PHILIP DAVID, MOSCOVITCH, MORRIS, THOMPSON, EVAN (Eds.) (2007), The Cambridge Handbook of Conciousness, Cambridge, Cambridge University Press.

Universidad Autónoma de Madrid

Cátedra Ciencia, Tecnología y Religión, Universidad Comillas, Madrid jmonserrat@comillas.edu

JAVIER MONSERRAT

[Artículo aprobado para publicación en enero de 2019] 